\title{
Separation procedures in the identification of the hydrogenation products of biomass-derived hydroxymethylfurfural
}

https://doi.org/10.1515/revac-2020-0106

Received May 21, 2020; accepted July 03, 2020

Abstract: Lignocellulosic biomass is considered an attractive and most abundant renewable carbon feedstock. Hydroxymethylfurfural (HMF) is one of the platform molecules obtained from biomass. HMF transformation in the reductive atmosphere allows to obtain numerous value-added molecules with applications in several recently emerged sectors, e.g. biofuels and biopolymers. This process is still intensively investigated, and more efficient, stable and sustainable solutions are envisaged. Therefore, the choice of efficient analytical methods is of great importance. This review covers the methodologies used for the analysis of HMF hydrodeoxygenation, including chromatographic and spectrometric methods. Techniques such as gas chromatography, highperformance liquid chromatography, Fourier transform infrared spectroscopy, nuclear magnetic resonance, and mass spectrometry are mentioned as well in this review.

Keywords: separation techniques, gas chromatography, liquid chromatography, nuclear magnetic resonance, hydroxymethylfurfural deoxygenation

\section{Abbreviations \\ 2-MF - 2-methylfuran \\ 2-MTHF - 2-methyltetrahydrofuran \\ 5-MF - 5-methyl furfural \\ 5-MFA - 5-methylfurfural alcohol}

BHMF - 2,5-bishydroxymethylfuran

BHMTHF - 2,5-bis(hydroxymethyl)tetrahydrofuran

BPMF - 2,5-bis(isopropoxymethyl)-furan

DCM - dichloromethane

DFF - 2,5-diformyl furan

DMF - 2,5-dimethylfuran

DMSO - dimethylsulfoxide

DMTHF - 2,5-dimethyltetrahydrofuran

EFA - mono-ether-furfural alcohol

EMMF - ether 2-(ethoxymethyl)-5-methylfuran

FA - furfural

FFMF - (5-formylfuran-2-yl)methyl formate

FID - flame ionization detector

FOL - furfuryl alcohol

GC - gas chromatography

GVL $-y$-valerolactone

HA - 2-hexanol

HD - 2,5-hexanedione

HMF - 5-hydroxymethylfurfural

HMFCA - 5- hydroxymethyl-2-furancarboxylic acid

HT - hexanetriol

MFM - 5-methyl-2-furanmethanol

MIBK - methyl isobutyl ketone

MTHFA - 5-methyltetrahydrofurfuryl alcohol

NMR - nuclear magnetic resonance

TCD - thermal conductivity detector

THF - tetrahydrofuran

THF2A - tetrahydro furfural

THFA - tetrahydrofurfuryl alcohol

\section{Introduction}

Lignocellulosic biomass is considered the most abundant source of renewable carbon. Taking into account the depletion of the fossil fuel reserves, biomass constitutes a very attractive sustainable carbon feedstock. In the last decade, we could observe an increasing interest in the development of bio-based processes allowing to reach 
high yields of newly emerged products like biofuels or various platform molecules [1-5]. Those processes provide new, more advanced functionality of biomass-derived raw materials, which is often allowed by precisely tailored oxygen content [6].

Following this, 5-hydroxymethylfurfural (HMF) has since the last decade of the 19th century been considered a valuable platform molecule, which is broadly illustrated in excellent reviews on this topic [7-10]. It is obtained from lignocellulosic biomass via a multi-step reaction, with acid hydrolysis of lignocellulose being the first step, followed by dehydration of glucose or fructose in the presence of acid catalysts (Scheme 1). Due to the higher selectivity, fructose is considered as the preferred source allowing to obtain high HMF yield. [11].

Thanks to the high functionalization of HMF, i.e. both hydroxyl and carbonyl groups in its structure, it possesses a high potential to be catalytically transformed to multiple industrially relevant products of both oxidation [12,13] and reduction reactions [7]. Particularly its hydrodeoxygenation provides a series of added-value molecules possessing a wide range of applications. Among the products of the HMF reductive transformation (Scheme 2) there are 2-methyltetrahydrofuran (2-MTHF), known as an appealing eco-friendly aprotic ether solvent and biofuel additive, 2,5-bishydroxymethylfuran (BHMF), a potential substrate for biopolymer production [14,15], or 2,5-dimethylfuran (DMF), a biofuel [16], among others.

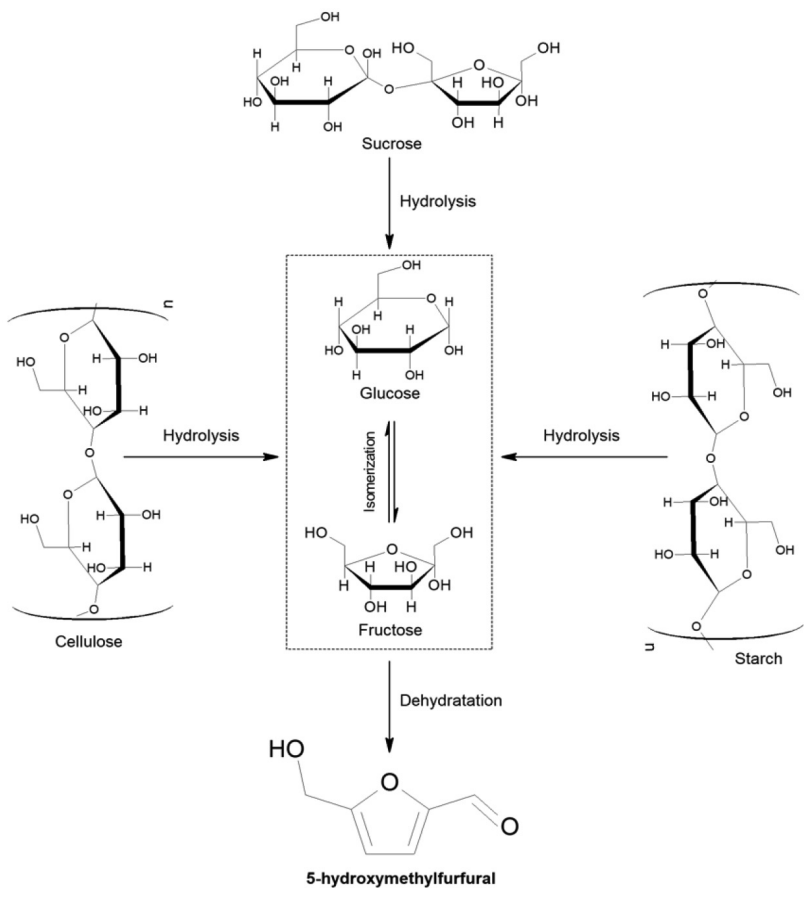

Scheme 1 Synthesis of HMF from biomass.
As illustrated in Scheme 2, HMF transformation in the reductive atmosphere involves several processes like hydrogenation of the $\mathrm{C}-\mathrm{O}$ bond, hydrogenation of the furan ring, $\mathrm{C}-\mathrm{O}$ hydrogenolysis, or polymerization. The selectivity of this reaction strongly depends on the reaction conditions, including the catalyst used [8]. This process is still intensively investigated, and more efficient, stable and sustainable solutions are envisaged. The vast potential of this reaction is however partly overshadowed by analytical difficulties which are often faced by researchers. The bottlenecks are associated with the closure of the carbon balance for all reaction products, their separation and identification.

HMF hydrodeoxygenation products can be of high complexity. Therefore, specific, comprehensive, and robust analytical methodologies need to be used in order to understand the transformation pathways of this process and to work out new, more efficient solutions. This review concentrates on presenting various analytical methods and their potential, as to the best of our knowledge the analytical challenges of this process are omitted in most of the papers. Although high-resolution chromatographic techniques are fundamental for the characterization of HMF value-added reaction products, they are not exclusive. This work provides an overview of the current state of the art, the main challenges that still need to be addressed, and improvements concerning more robust, sustainable and efficient separation processes.

\section{HMF separation from cellulose/ sugars}

The most conventional methods of HMF synthesis include acid-catalyzed dehydration of monosugars obtained from biomass. HMF is obtained from fructose rather than glucose because the ring structure of glucose is more stable and therefore fructose reacts faster [17]. Water is usually used as a reaction solvent, although unfortunately it accelerates the consecutive side reactions and consumes HMF. It is worth noting that the formation of HMF by sugar dehydration is a complicated process due to the possibility of many side reactions. As a result of decomposition of fructose in water at high temperatures, isomerization, dehydration or condensation products may be formed. That is why the process is usually carried out in a biphasic system in order to extract HMF from the aqueous phase or aprotic organic solvents like dimethylsulfoxide (DMSO). The used organic solvent reduces the HMF degradation and the formation of by-products such as soluble polymers or humines, among others [18]. The most commonly used solvents include ethyl 


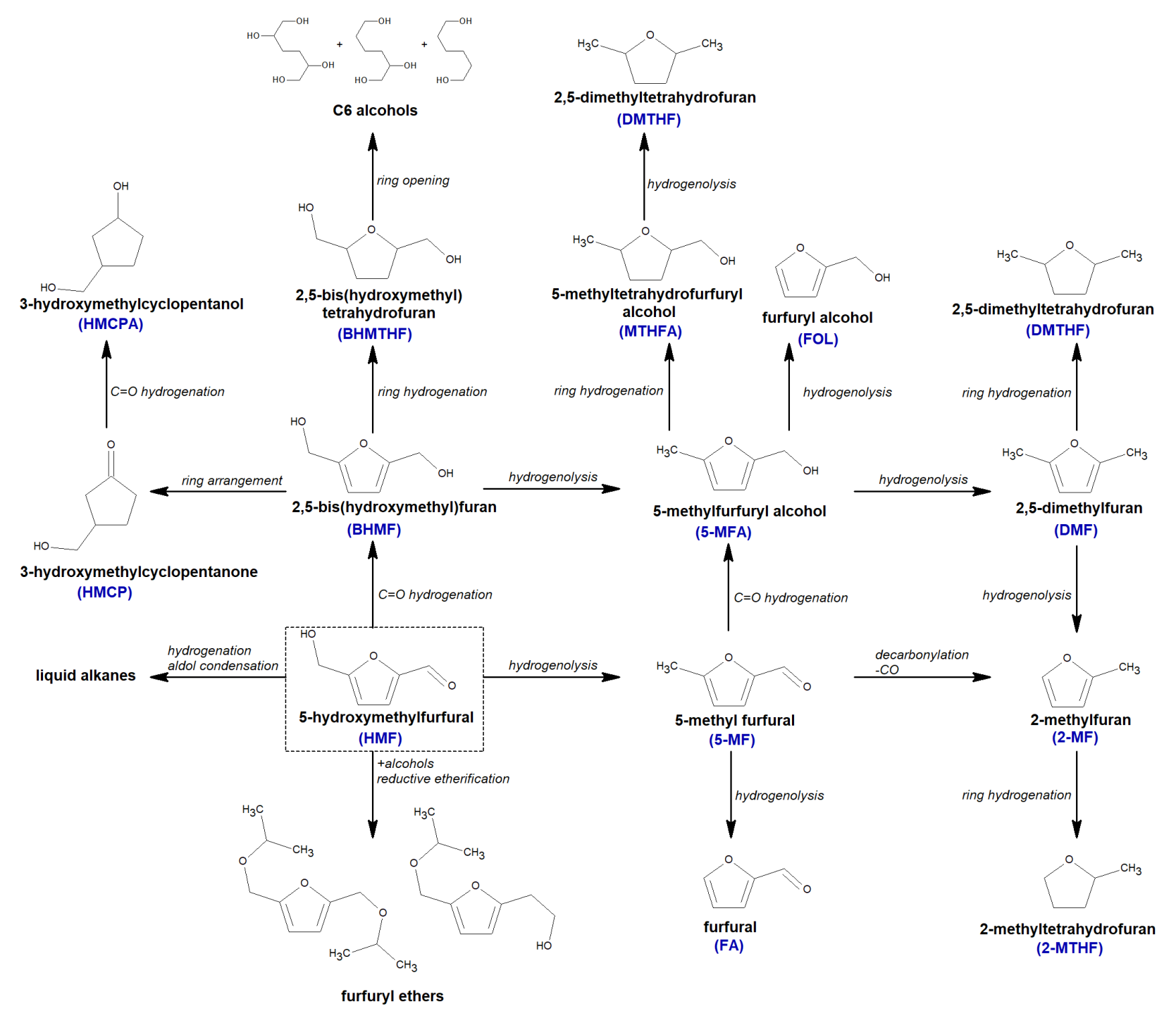

Scheme 2 Conversion of HMF to valuable chemicals.

acetate, diethyl ether, and ionic liquids or methyl isobutyl ketone (MIBK) [19-22]. In literature, there are also numerous examples of efficient use of biphasic systems for direct HMF production from sugars. Biphasic system $\mathrm{MIBK} / \mathrm{H}_{2} \mathrm{O}$ together with different zeolite catalysts was used for the HMF production and its efficiency was much higher in comparison to water only $[23,24]$. Biphasic $\mathrm{THF} / \mathrm{H}_{2} \mathrm{O}$ systems modified with $\mathrm{NaCl}$ together with $\mathrm{FePO}_{4}$ and $\mathrm{NaH}_{2} \mathrm{PO}_{4}$ as catalysts show a potential as an efficient solvent system as well [25]. Advanced approach related to the design of a biphasic reactor system composed of the aqueous phase modified with DMSO, combined with an organic extracting phase composed of MIBK-2-butanol mixture or dichloromethane (DCM) was shown by the group of Dumesic. By using the modified conditions tuned for the specific feedstock this reactor allows to obtain HMF with good selectivities at high conversions, independently of the feedstock [26].
Another approach includes environmentally friendly solvents like 2-MTHF, $y$-valerolactone (GVL) or 1-butanol are considered as good bio renewable, sustainable alternative solvents, as they are effective, stable, and reasonably cheap [27].

\section{Analytical techniques used for the analysis of HMF conversion products}

HMF hydrodeoxygenation has been continuously explored in the literature. In order to avoid side reactions, the selectivity to the main products is tuned by the change of reaction conditions (temperature, pressure, hydrogen source, solvent) and the use of proper catalysts. A large group of catalysts is based on noble metals ( $\mathrm{Pd}, \mathrm{Au}, \mathrm{Pt}$, $\mathrm{Ru})[7,8]$. Non-noble metal-based catalysts are more 
appealing due to lower cost and availability, but harsher experimental conditions are generally required in their presence [28]. Electro- and photo-assisted approaches to catalytic hydrogenation are examples of a greener methodology found in the literature. Competitive side reactions, which are often co-catalyzed by the same system or are also sensitive to the experimental conditions, are however difficult to avoid. In turn, this requires complex analytical systems. This section is divided into two parts and will be related to the analysis of the reaction products by gas and liquid chromatography, Fourier transforms infrared spectroscopy and nuclear magnetic resonance spectroscopy.

\section{Gas and liquid chromatography}

For several decades, gas chromatography (GC) has been one of the most popular techniques for the detection, identification and separation of volatile and semi-volatile analytes, in complex, including biomass-related samples $[29,30]$. GC usually concentrates on the volatile organic species with lower polarity and lower boiling point $\left(<350^{\circ} \mathrm{C}\right)$ [31].

Different detectors are applied in GC analysis due to the different resolutions and sensitivities to specific molecules. For instance, GC-MS is rather established as a semi-quantitative tool, for which the limitation is additionally related to its lack of capability of direct analysis of nonvolatile or polar compounds.

In the case of highly polar analytes, a derivatization step is usually required in order to increase both volatility and thermal stability of the analyzed species. This procedure can increase the detector response by incorporating functional groups which lead to higher detector signals and in consequence to improved GC separation performances [32,33]. Multiple derivatization reactions like silylation, alkylation, or acylation can be used to mask the polar functional groups [34].

Several different derivatizing procedures are used in the case of the HMF analysis. They are mostly based on the formation of silylated derivatives with the use of different reagents. Among the derivatizing reagents examined, N,Obis-trime- thylsilyltrifluoroacetamide (BSTFA) provided very good deri- vatization yields, while those examples are usually limited to food analysis [35].

The strong advantage of GC-MS is related to the high reproducibility of the generated mass spectra using electron impact ionization (EI). EI is a hard ionization process that results in the production of very reproducible mass spectra independently of the instrument used - in consequence, it allows the use of broad EI-mass spectral libraries [36]. EI fragmentation can be however sometimes too powerful and extensive so that softer ionization techniques such as chemical ionization (CI) can enhance the detection of molecular ion-based species.

Flame ionization detectors (FID) are most commonly used. Due to their broad detection limits, they can measure organic substance concentration at very low $\left(10^{-13} \mathrm{~g} / \mathrm{s}\right)$ and very high levels, having a linear response range of $10^{7} \mathrm{~g} / \mathrm{s}$. Here the analysis strongly depends on the column choice and methodology applied, as the separation depends on the interaction of the substances with the stationary phase in the chromatography column. One of the important features of GC column is the kind of its active phase. Interaction between solutes and stationary phases decides about the separation of different solute molecules. For typical stationary phases like polysiloxanes and polyethylene glycols, three factors are crucial: dispersion, dipole-dipole interaction and hydrogen bonding interaction. The presence of the dipole-dipole interaction can enhance the separation of solutes like in the case of polyethylene glycols phase. The stationary phases that undergo dipole-dipole interactions also undergo hydrogen bonding interactions that also strongly influence the separation. The latter interaction is present when there is hydrogen bonding between the solute molecules and the stationary phase. Another key issue is the column polarity, which can strongly affect the separation of the solutes. For the molecules of similar volatility, higher retention time is obtained for the molecules possessing similar polarity to the polarity of the stationary phase [37]. In the broad range of presented examples (Table 1), FID was the most commonly used and high-polarity columns (like WAX) with the polyethylene glycol polymer phase were often applied. They are known to be good in the separation of many nonhalogenated organics, free C1-C26 fatty acids, alcohols, diols including glycols, and many other chemicals with different nature. When it comes to the subject of this review, the product identification efficiency depends on many factors, of which one of the most important is the selectivity of HMF hydrodeoxygenation reaction and therefore the number of products to analyze, and their difference in volatility. There are some limited examples where only one GC detector was used for analysis (FID) $[38,39]$ and for selective reactions with the presence of only a few products (HMF, DMF, BHMF, 5-MFA) without many impurities it proved fully sufficient, practically allowing to close the carbon balance of the reaction [40-42]. However, where a wide range of by-products is present, FID is 


\begin{tabular}{|c|c|c|c|c|c|c|}
\hline $\begin{array}{l}\bar{\sigma} \\
m \\
\infty \\
m \\
m\end{array}$ & $\begin{array}{l}\infty \\
\stackrel{\infty}{\hat{n}} \\
\hat{\sim} \\
\end{array}$ & 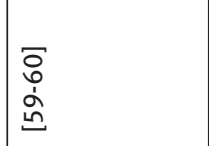 & $\vec{m}$ & 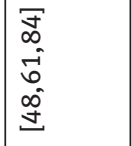 & 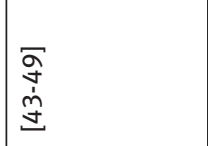 & \begin{tabular}{|l}
$\tilde{n}$ \\
$\varrho$
\end{tabular} \\
\hline 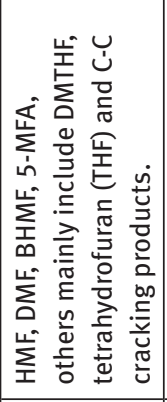 & 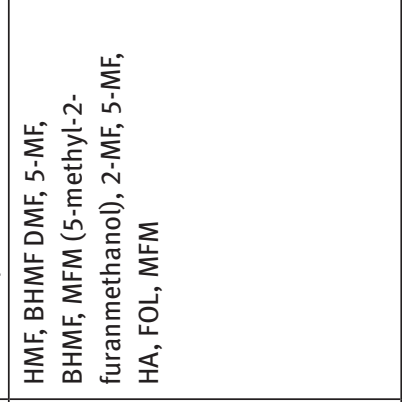 & 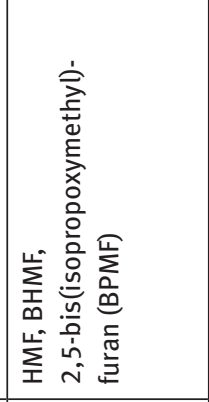 & 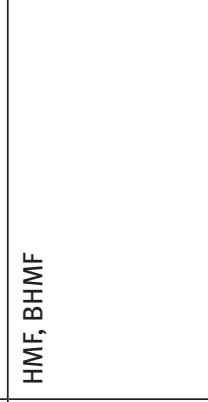 & 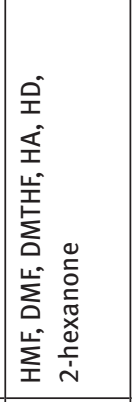 & 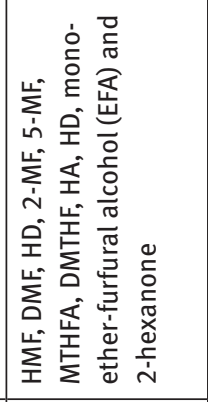 & 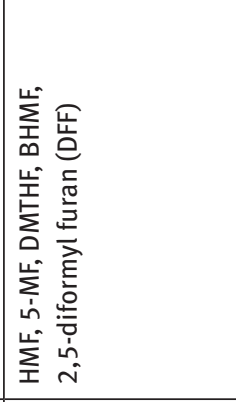 \\
\hline 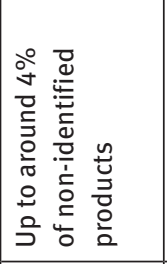 & 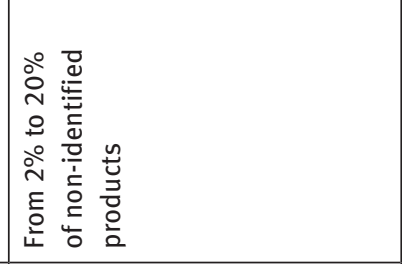 & 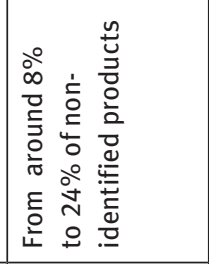 & 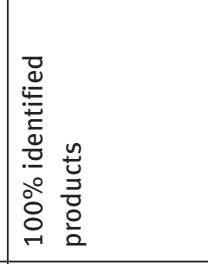 & 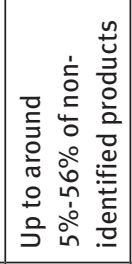 & 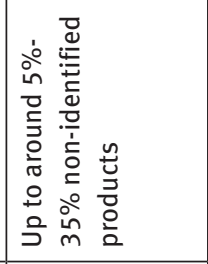 & 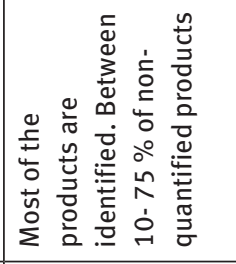 \\
\hline 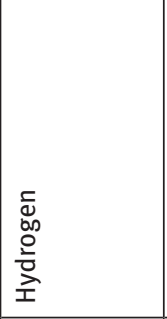 & 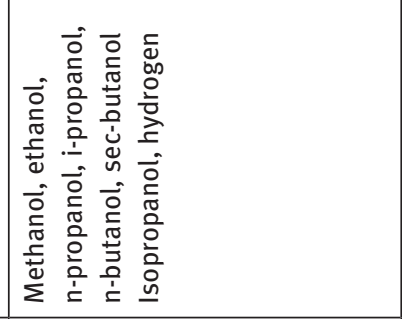 & 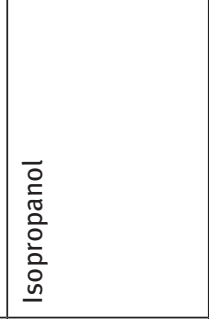 & 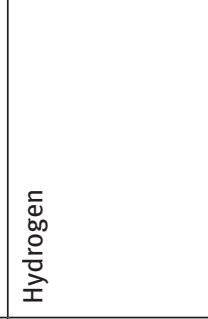 & 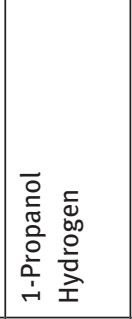 & 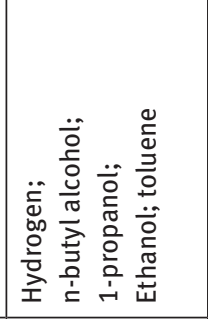 & 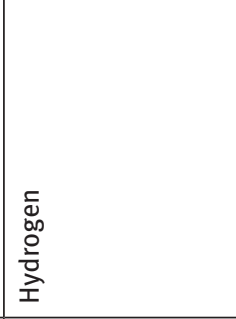 \\
\hline 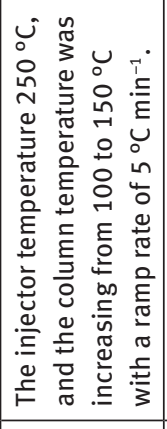 & 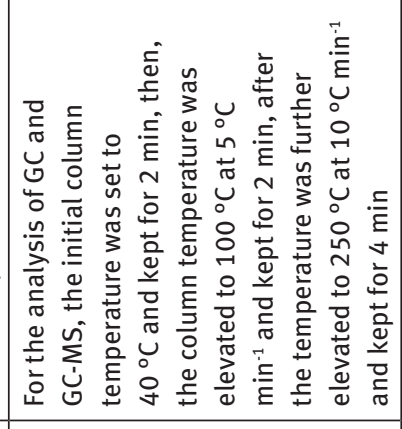 & 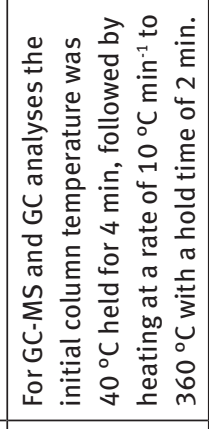 & 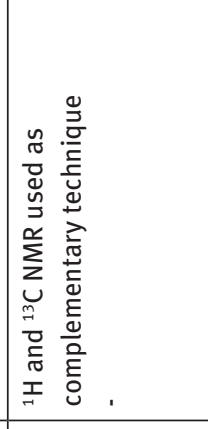 & & & 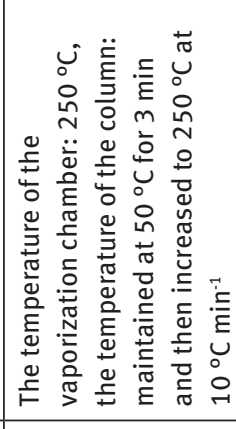 \\
\hline 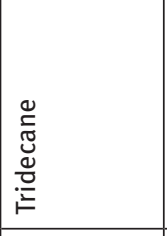 & 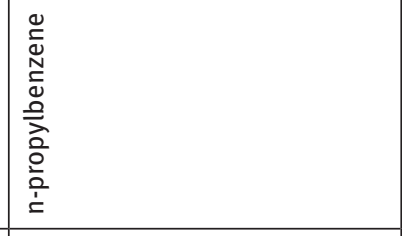 & 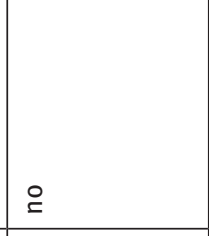 & ミ & 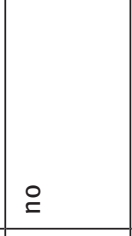 & 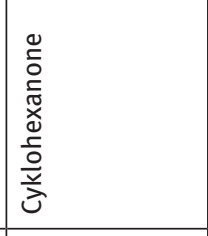 & 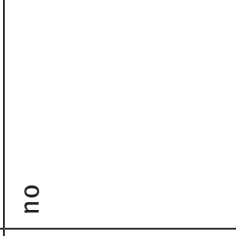 \\
\hline 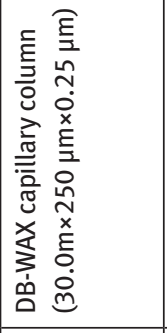 & 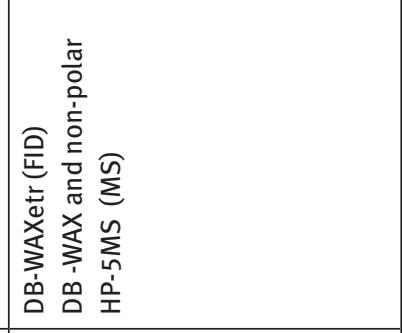 & 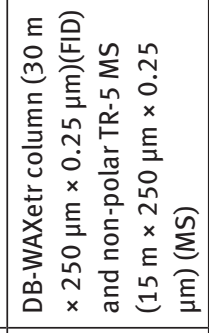 & 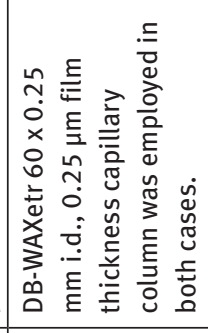 & 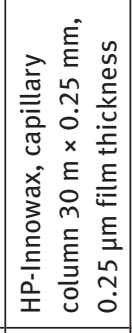 & 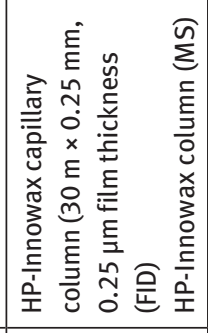 & 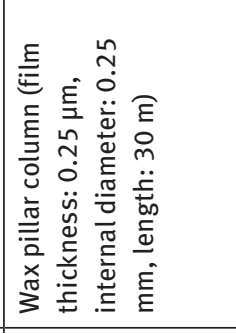 \\
\hline 은 & 은 $\frac{n}{\Sigma}$ & 은 $\frac{n}{\Sigma}$ & 은 $\frac{n}{\Sigma}$ & 은 & 은 $\frac{n}{\Sigma}$ & 은 $\frac{n}{\Sigma}$ \\
\hline
\end{tabular}




\begin{tabular}{|c|c|c|c|c|c|c|}
\hline 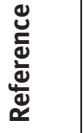 & 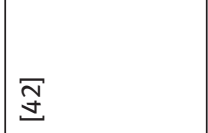 & 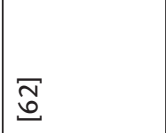 & 总 & $\vec{\Xi}$ & $\underline{\tilde{\tilde{e}}}$ & 正 \\
\hline 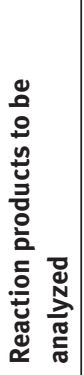 & 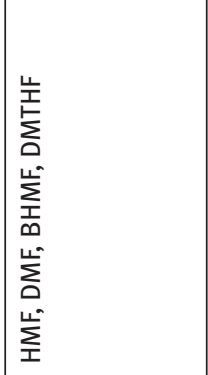 & 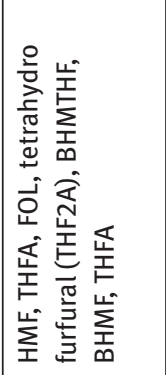 & 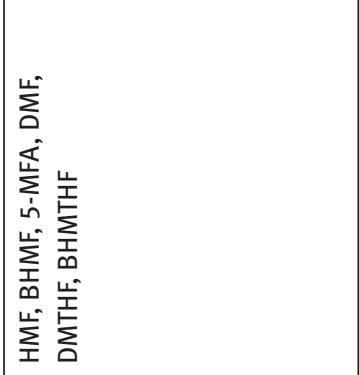 & 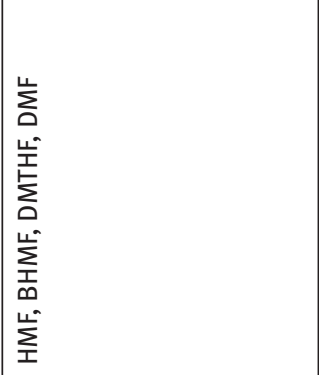 & 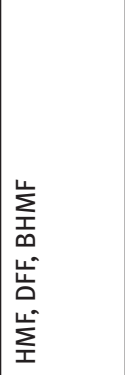 & 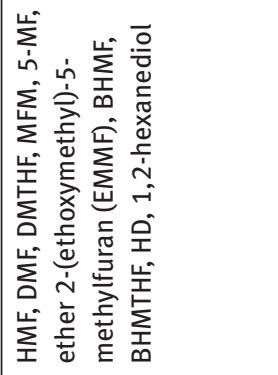 \\
\hline 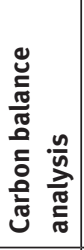 & 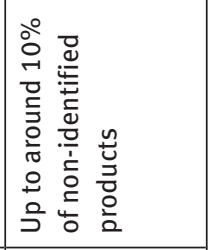 & 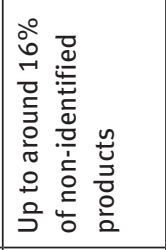 & . & 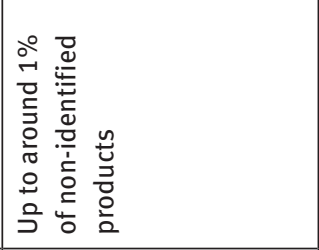 & 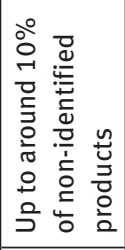 & 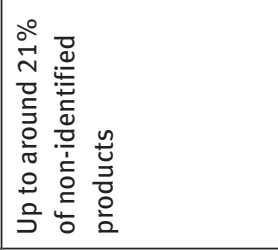 \\
\hline 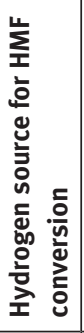 & 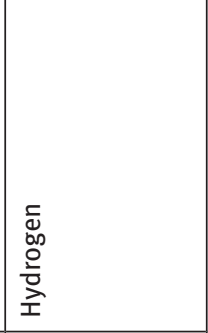 & 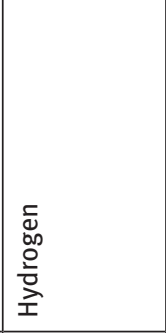 & 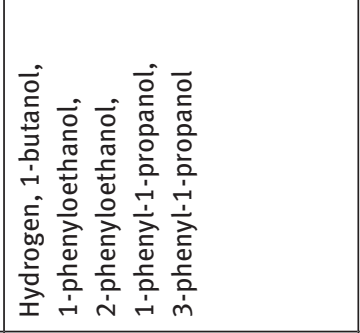 & 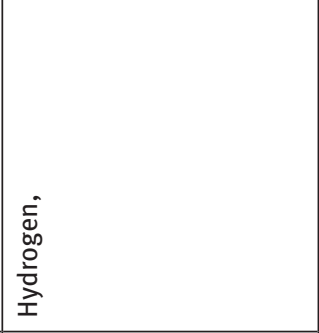 & & 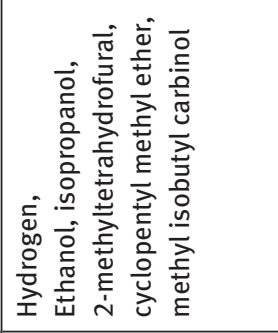 \\
\hline 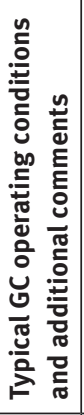 & 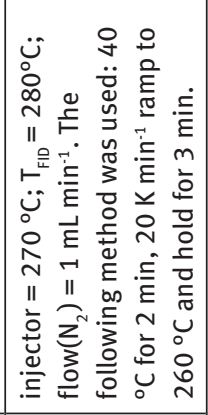 & . & 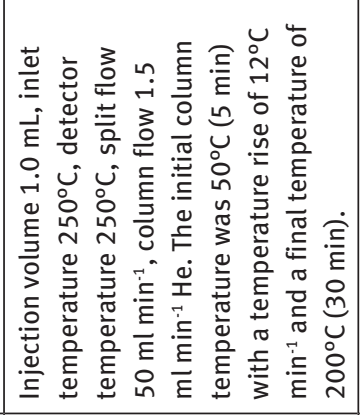 & 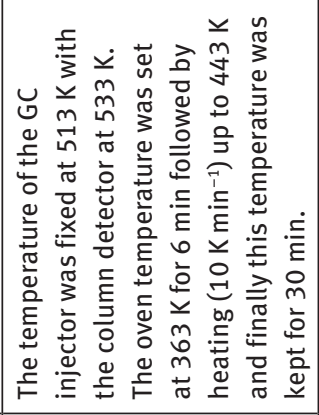 & . & 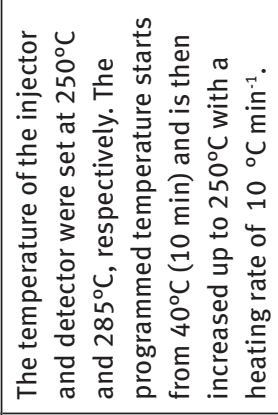 \\
\hline 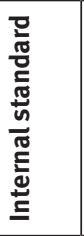 & 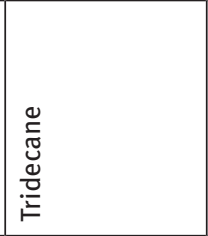 & 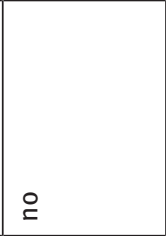 & 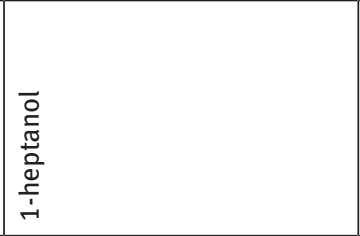 & 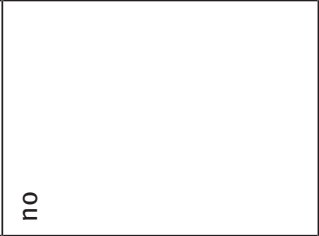 & 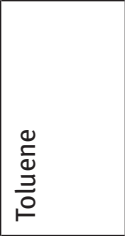 & 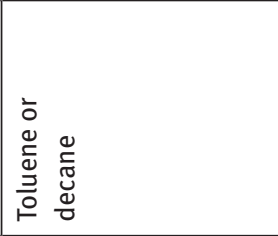 \\
\hline $\begin{array}{l}\overline{\mathrm{g}} \\
\overline{\mathrm{J}}\end{array}$ & 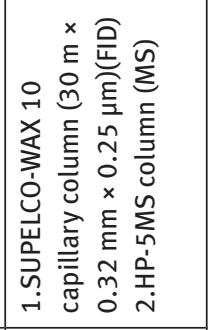 & 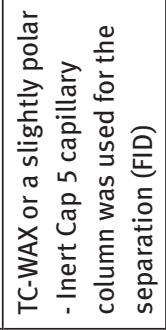 & 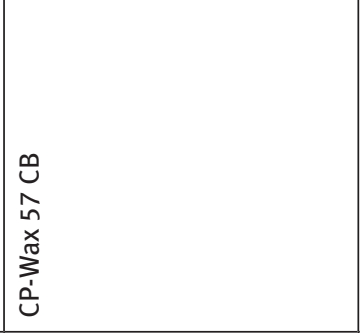 & 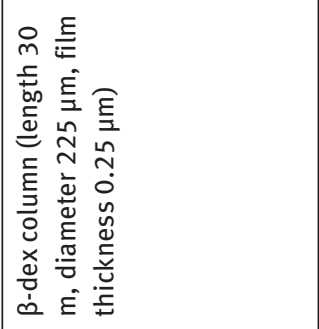 & 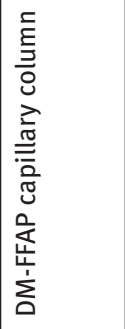 & 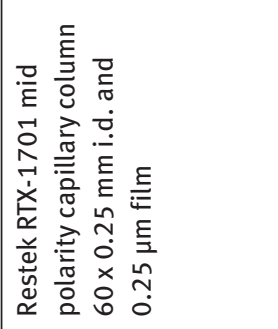 \\
\hline 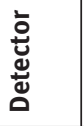 & 은 $\frac{n}{\Sigma}$ & 은 ${ }^{n} \Sigma$ & 은 & 은 & 은 & 은 \\
\hline
\end{tabular}


often combined with MS detector or NMR spectroscopy analysis, which allow the structure confirmation [42-48] and therefore more complete detection. This combined technique allows to nearly fully identify and quantify all reaction products $[40,46,49]$. An interesting example of analysis is described in the work of Chimentão et al. [41] with the use of GC-MS equipped with a $\beta$-dex column containing permethylated $\beta$-cyclodextrin embedded in an intermediate-polarity stationary phase. Those types of phases are recommended for analysis of chiral compounds like ketones, alkanes, alkenes, alcohols, acids, ethers, etc. Performing the mass spectrometry allowed to compare the mass spectral patterns $(\mathrm{m} / \mathrm{z})$ of the compounds in the reaction mixture. The most intense peaks in the mass spectrum (notably m/z: 97 and 126 for HMF, 128 and 97 for BHMF, 56 and 41 for DMTHF, 96 and 95 for DMF) allowed to identify HMF and the reaction products [41]. Analytics was as well established in detail way in the work of Gyngazova et al. [50]. The study focused on understanding the reaction kinetics of HMF hydrogenation. Thanks to the identification of products (2-MF, 5-MFA, DMTHF, BHMF, BHMTHF and 2-MTHF) in a presence of different solvents by GC-FID with CP-Wax 57, the authors [50] understand the reaction network and explained that it proceeds via the hydrogenation of HMF aldehyde group to form BHMF and the subsequent conversion of BHMF to 5-MFA, followed by its to DMF. Side reactions include the formation of BHMTHF and DMTHF. The proposed analysis did not allow however to close the carbon balance. This could be caused by polymeric side reaction products in the reaction mixture which could not be analyzed by the current device [50].

Also, in the work of Li et al., a very detailed GC-MS analysis did not allow to close the carbon balance [57]. When THF was used as a solvent, different unidentified peaks with high molecular weights of ca. 200-250 could be identified in the GC-MS spectrum. Only HMF dimer with a molecular weight of 190 was identified, suggesting that a polymerization catalyzed by the Lewis acidity of the Fe catalysts can take part. Therefore, it was concluded that the Lewis-acid-catalyzed polymerization formed humins and other polymers, that could not be identified by GC-MS.

The side products resulting from HMF polymerization products during the hydrogenation reaction were however analyzed in the work of the group of Sun et al. [65] thanks to the use of fluorescence spectrometer. In this work, the reaction network was examined in detail and the liquid reaction products were analyzed with a GC-MS with a Wax pillar column. GC-MS spectra allowed to identify the majority of the products, although not all were analyzed in the quantitative manner [65]. Among the factors that increase the number of by-products, the authors included side reactions like polymerization, dehydration and the furan ring opening, that can be co-catalyzed by the presence of acid/basic sites in the used catalyst.

On the other hand, there are several examples where non-polar or low-polarity columns, like HP-5, or AB-5 with (5\%-phenyl)-methylpolysiloxane, or CP-Sil 5 containing $100 \%$ dimethylpolysiloxane phase, are used (Table 2). Those columns are quite popular for general purposes in a broad range of applications. Their advantage is the high temperature limit. When a small number of reaction products were observed [66], the carbon balance was nearly fully closed. Of course, typical internal standards (e.g. tetradecane, tridecane, or naphthalene) were often used to improve the quantitative analysis of the products. Typically, an MS detector with EI ionization or even liquid chromatography was used for improved analysis [67,68].

A very interesting example is provided in the work of $\mathrm{Hu}$ et al. [69] showing a detailed analysis of by-products provided by the use of GC-FID with HP- 5 column, with confirmation of the DMF structure by GC-MS and NMR and FT-IR. Moreover, the authors established a detailed separation procedure of DMF from the by-product mixture (2,5-hexanedione (HD), 2-hexanol (HA), FOL and tetrahydrofurfuryl alcohol (THFA)) based on distillation and fractionation. This allowed to obtain $98.9 \%$ purity of the final product (DMF). Additionally, the structure of all the reaction products was confirmed by GC-MS analysis, which allows to propose a plausible mechanism of the reaction [69].

In order to increase the sustainability aspect, the reaction is frequently performed with internal hydrogen source like formic acid. In this case for closing the carbon balance, it is obligatory to use a thermal conductivity detector (TCD) for analyzing the gaseous substances, like in the work of Zhang et al. [67] and Yu et al. [68]. Three GC detectors FID, MS, TCD were used for the analysis of the HMF conversion products in the hydrogenation with $\mathrm{Ni}-\mathrm{Fe}$ catalysts with the use of different solvents. Besides the typical reaction products HMF, BHMF, 5-methyl-2furanmethanol (MFM), DMF, and DMTHF, as well as the starting material, the authors identified different ethers, products of decarbonylation and ring-opening product, and humins [68].

In some cases, the presence of large amounts of nonanalyzed products is related to several factors. Firstly, often the research focuses only on the key molecules obtained in high yield [84], whereas the analysis of side products is omitted. Another reason is the complexity of the analysis itself. In the HMF valorization under hydrogen atmosphere, the by-products are of similar 


\begin{tabular}{|c|c|c|c|c|c|}
\hline 岕 & $\begin{array}{l}\bar{m} \\
\hat{N} \\
\dot{\rho}\end{array}$ & $\underset{\Xi}{\Xi}$ & $\begin{array}{l}\sqrt{2} \\
2 \\
n \\
0 \\
0 \\
0\end{array}$ & 宓 & $\sqrt{6}$ \\
\hline 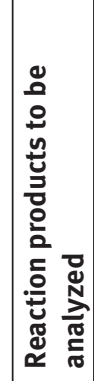 & 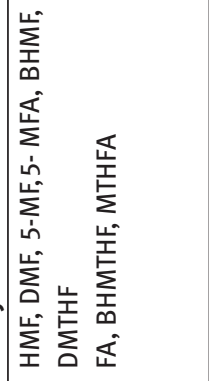 & $\sum_{\substack{I \\
\infty}}^{\text {Lut }}$ & 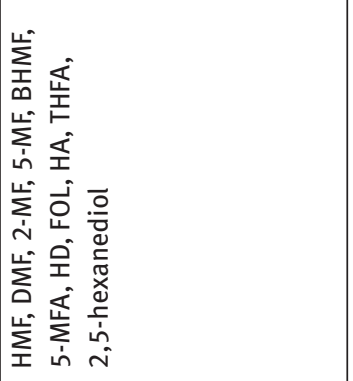 & 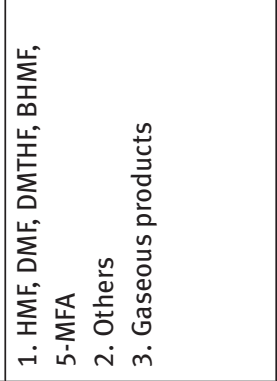 & 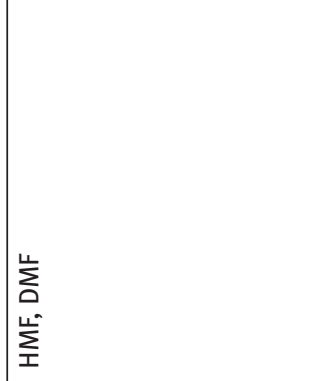 \\
\hline 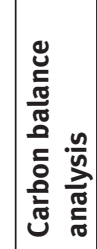 & 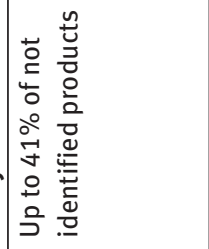 & 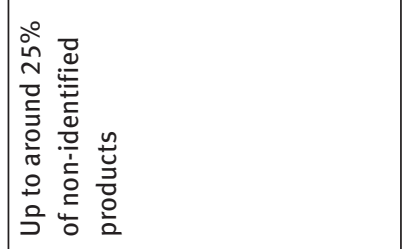 & 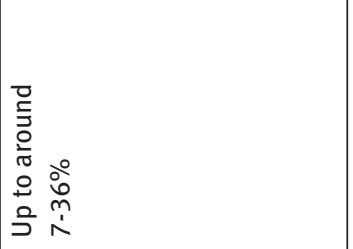 & 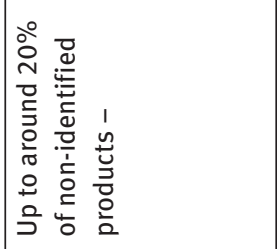 & 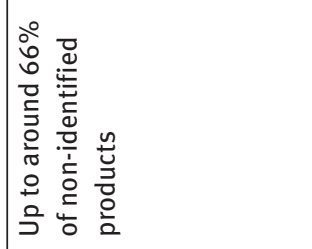 \\
\hline 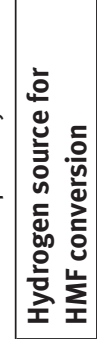 & 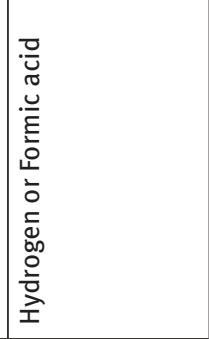 & 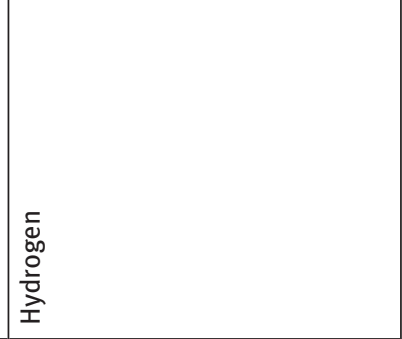 & 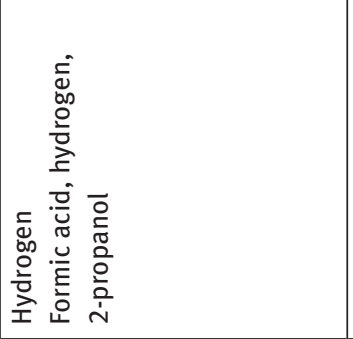 & 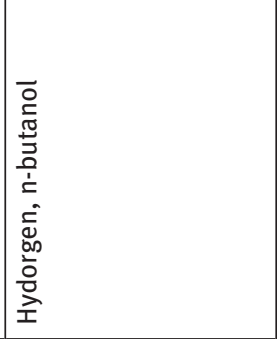 & 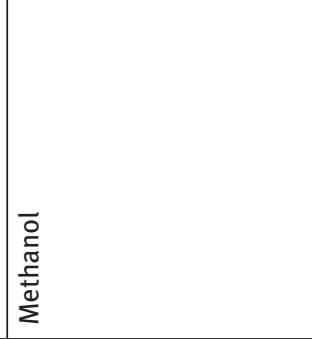 \\
\hline 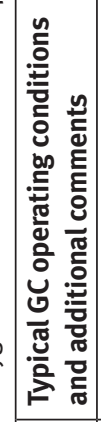 & 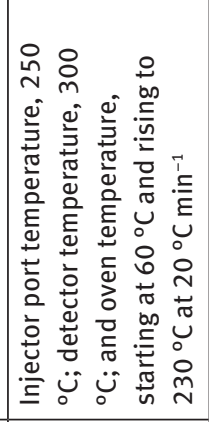 & 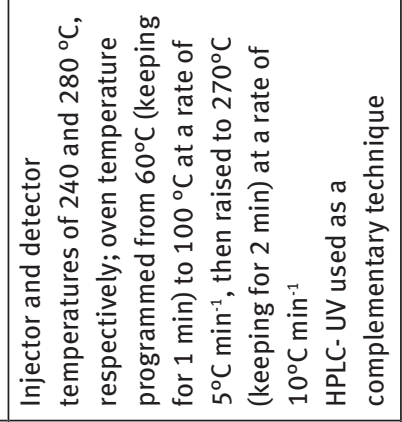 & 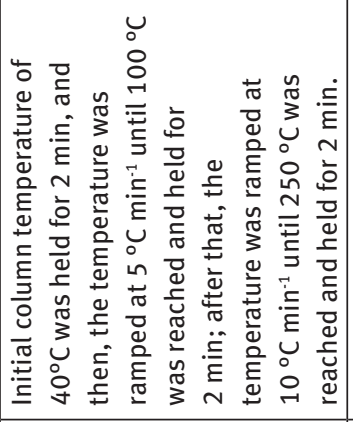 & . & 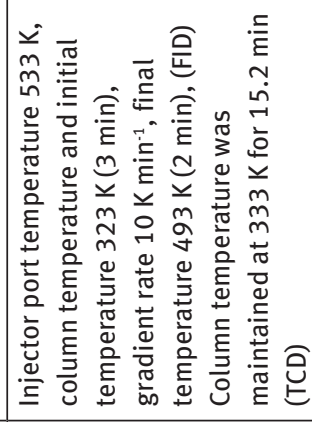 \\
\hline 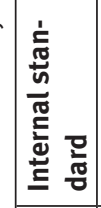 & 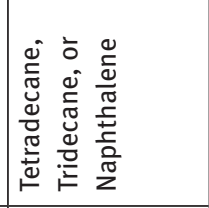 & 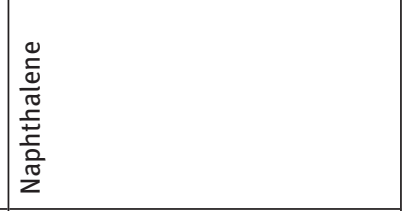 & & $\stackrel{\circ}{\check{1}}$ & 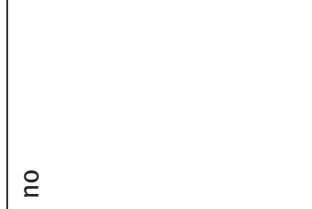 \\
\hline 衰 & 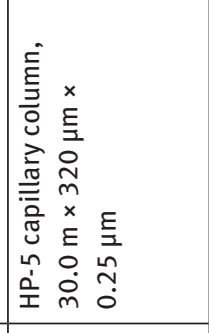 & 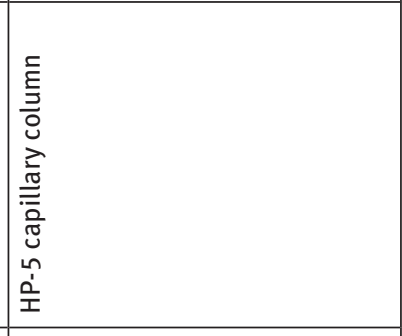 & 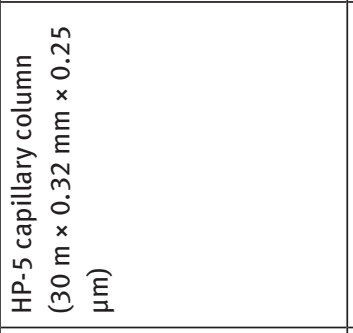 & 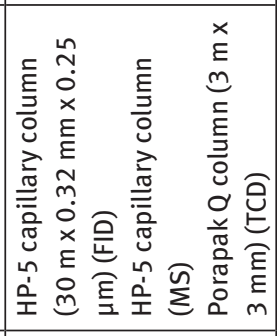 & 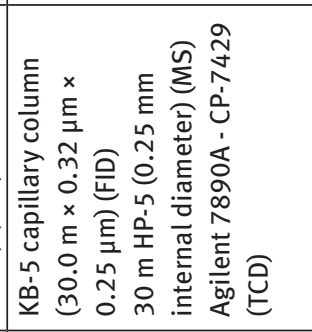 \\
\hline 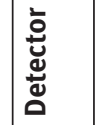 & 은 & 은 & 은 $\sum^{n}$ & 은 只 仓 & 은 氝 은 \\
\hline
\end{tabular}




\begin{tabular}{|c|c|c|c|c|c|c|}
\hline 亗 & 递 & $\begin{array}{l}\infty \\
\stackrel{\infty}{N} \\
\stackrel{2}{\Sigma}\end{array}$ & $\begin{array}{l}\sigma \\
\infty \\
\stackrel{D}{\Sigma}\end{array}$ & $\overrightarrow{\underline{\infty}}$ & $\underset{\infty}{\widetilde{\infty}}$ & $\underline{\underline{\infty}}$ \\
\hline 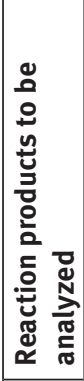 & 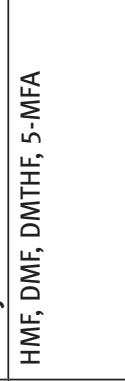 & 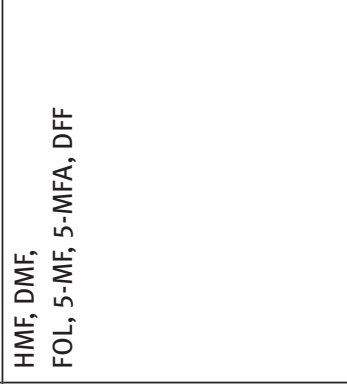 & 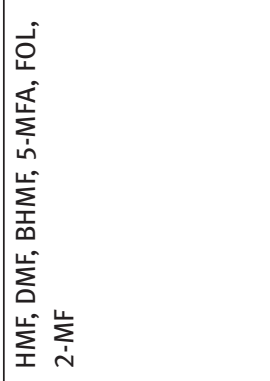 & 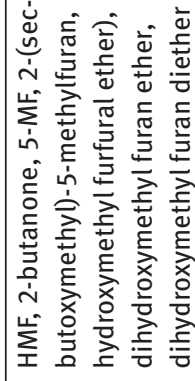 & 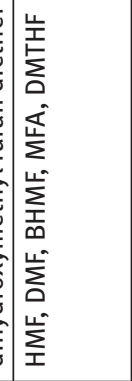 & 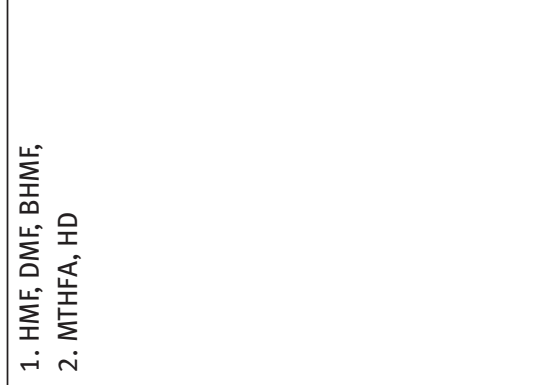 \\
\hline 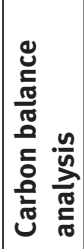 & 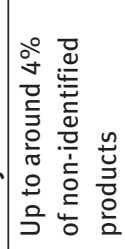 & . & 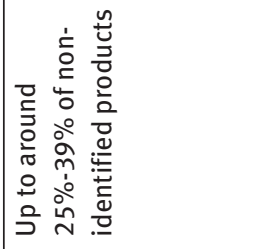 & 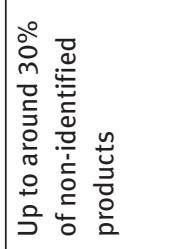 & 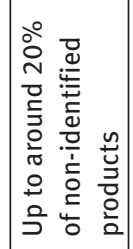 & 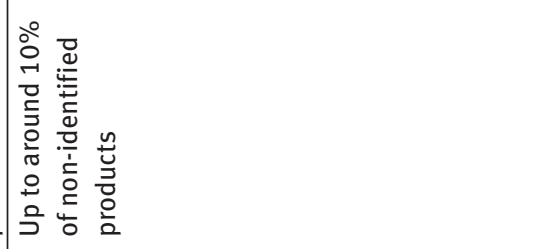 \\
\hline 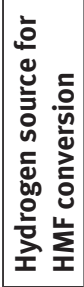 & 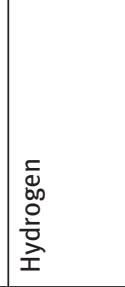 & 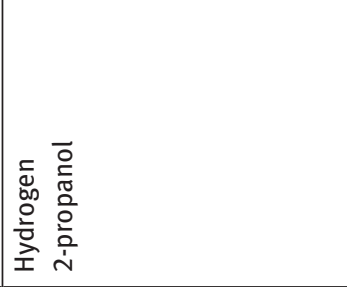 & 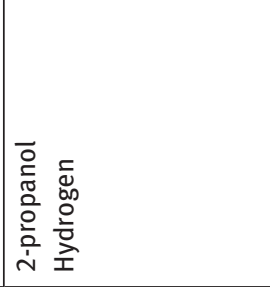 & 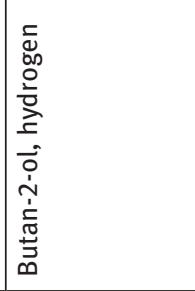 & 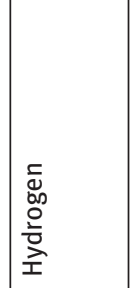 & 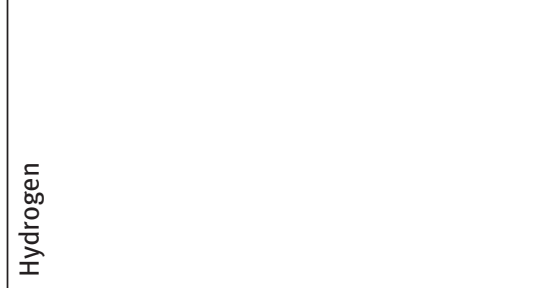 \\
\hline 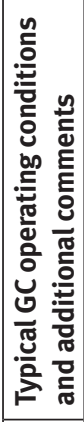 & & 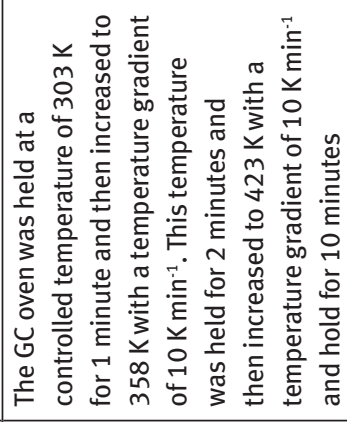 & 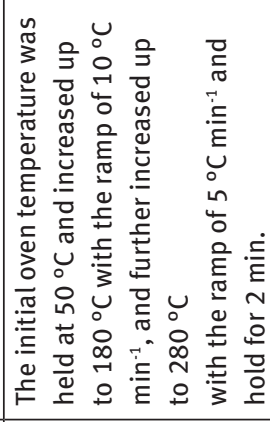 & . & & 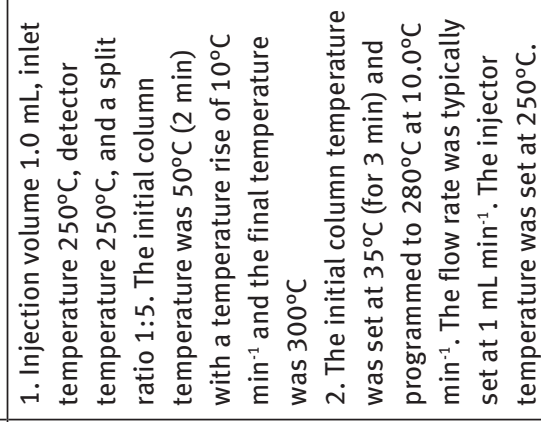 \\
\hline 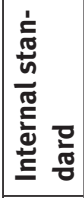 & 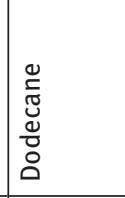 & 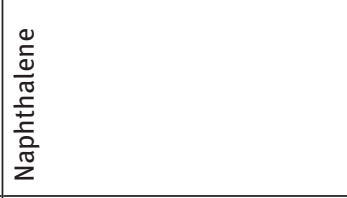 & . & . & 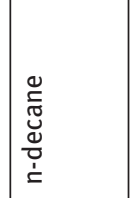 & \\
\hline 产 & 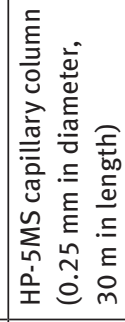 & 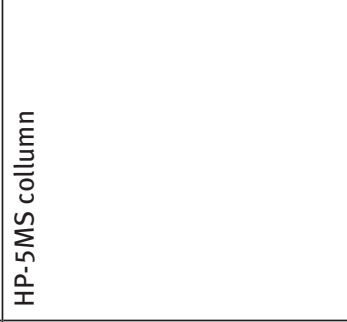 & 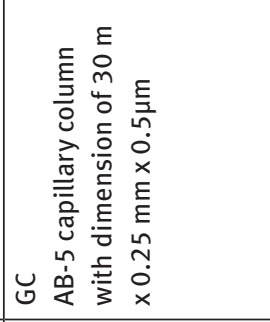 & 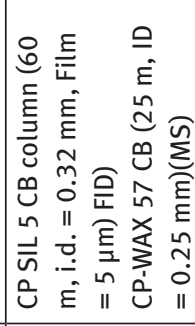 & 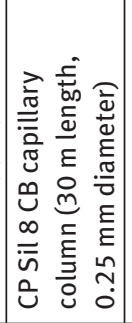 & 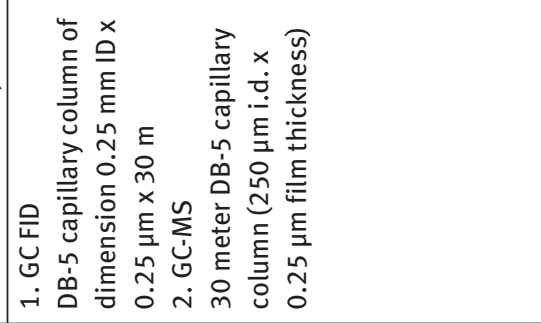 \\
\hline 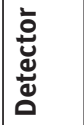 & 은 $\sum^{n}$ & 은 & 은 & 은 $\sum^{n}$ & 은 $\sum^{n}$ & 은 $\sum^{n}$ \\
\hline
\end{tabular}


chemical properties, particularly volatility, which can make the analysis difficult. Additionally, by-products are present in small quantities in comparison to the main reaction product. On the other hand, side reactions lead to various kinds of products, e.g. polymers or C1-C2 compounds present in the gas phase. The $\mathrm{C} 1$ products can also be formed when another, the more sustainable hydrogen source is used, e.g. formic acid. Its non-selective decomposition can produce $\mathrm{CO}$ and $\mathrm{CH}_{4}$ [85] that even in small quantities can poison the catalyst used for the HMF hydrodeoxygenation. This requires the use of complex analysis tools, including several techniques.

Liquid chromatography is more frequently used for the analysis of the compounds possessing lower vapor pressure, lower thermal stability and higher polarity or samples where water was used as a solvent. However, its limitations include the lower resolution or sensitivity of the columns to different impurities related to the catalyst leaching to the reaction solvent. Various HPLC detectors have been used for analyte characterization. Detectors based on the absorption of light in the ultraviolet and visible ranges are the most common, as they respond to a wide variety of compounds with satisfactory sensitivity. The same holds for the photodiode array detector (PDA) since besides producing a typical chromatogram it can deliver the UV/VIS scan of every component.

There are some examples shown in Table 3 of HPLC analysis with the use of standard UV-VIS or PDA detectors, that typically were performed with a gradient of two solvents $[86,87]$. Due to the complexity of the reaction mixture, this analysis was usually limited to the identification of two reaction products [86]. Otherwise, examples, where HPLC with UV-VIS is a dominant analytical technique, are scarce. More typically, the UV-VIS detector was used in combination with other techniques. The refractive index detector (RID) thanks to its simplicity of analysis is often applied. It has a broad range of analyzed products but does not respond well to very low concentrations of measured samples, cannot be used in a gradient of solvents and as a result does not allow to provide information about the reaction products obtained with the lower yield.

However, when combined with UV-VIS and additionally GC, GC-MS and LC-MS [93,94], it allows to nearly close the carbon balance of obtained products.

The use of LC-MS combined with GC-MS and $\mathrm{H}^{1} \mathrm{NMR}$ was described in the work of Sun et al. and allowed to describe and understand the reaction mechanism of MF formation which occurred via esterification and hydrogenolysis, rather than decarboxylation reaction [91].

The potential of RID is often used for the analysis of sugars that are the HMF precursors or reaction impurities or by-products [94,95]. For complementarity of analysis it is often combined with GC [94] or with MS detector, allowing broader identification of the products [83]. A detailed study concerning analytical procedures of hydrogenolysis of 5-hydroxymethylfurfural towards 5-methylfurfural is shown by Sun et al. [91] who present clear examples of HPLC-MS of HMF, FFMF ((5-formylfuran2-yl)methyl formate and 5-MF and GC-MS of the HMF over hydrogenation products, combined also with NMR analysis. HPLC with UV-VIS also clearly shows that the product distribution was worked out elegantly. The authors however concentrated mainly on the main reaction product 5-MF, limiting the analysis of other products to the qualitative aspect. To complete the overview, the analysis of $\mathrm{C} 1$ gaseous products of the formic acid decomposition would be desirable.

Besides the necessary complete analysis of gaseous or liquid products formed during the hydrodeoxygenation of HMF, we would like to emphasize that an extended analysis of the reaction products might also request to investigate the deposition with a time of solid or polymeric carbonaceous products at the surface of the catalyst. Indeed, while this might help in closing the carbon balance, this also influences the catalytic performance with potential impact on both conversion and selectivity patterns, as well as on stability and reusability issues. Whether academic or industrial investigations are concerned, it is worth keeping always in mind that the criteria for selecting the adequate analytical tool should include the analysis time. Indeed, due to the high number of products with close functions, the analysis might remain time-consuming when a good chromatographic product separation is desired.

\section{Fourier transform infrared spect- roscopy (FTIR) and Nuclear magnetic resonance spectroscopy (NMR)}

Another technique worth describing is Fourier transform infrared spectroscopy (FTIR), which is frequently applied in the qualitative and quantitative analysis of organic substances [30]. The mid-infrared region is particularly used to reveal the presence of various functional groups in molecules, thanks to their characteristic absorption bands. Bands around $3050 \mathrm{~cm}^{-1}$ are commonly attributed to $\mathrm{C}-\mathrm{H}$ stretching vibrations indicating the presence of aliphatic hydrocarbons. Bands around $3300-3400 \mathrm{~cm}^{-1}$ correspond to $\mathrm{O}-\mathrm{H}$ stretching vibrations suggesting the presence of carboxylic acids or alcohols. Bands in the region of 1450 


\begin{tabular}{|c|c|c|c|c|c|c|c|}
\hline$\stackrel{4}{\ddot{\varpi}}$ & $\begin{array}{l}\Phi \\
\infty\end{array}$ & 当 & $\begin{array}{l}\infty \\
\infty \\
\infty\end{array}$ & $\overline{\underline{a}}$ & 芯 & $\begin{array}{l}\overline{\boldsymbol{\sigma}} \\
\infty\end{array}$ & ¿ \\
\hline 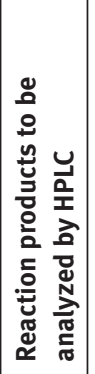 & 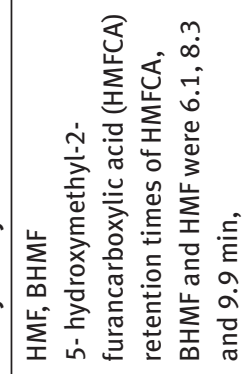 & 佡 & 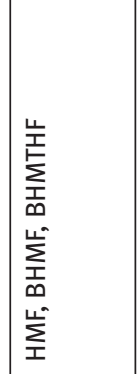 & 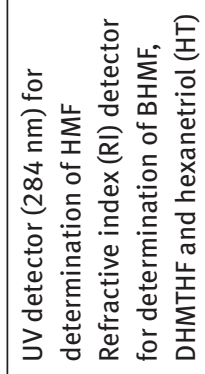 & 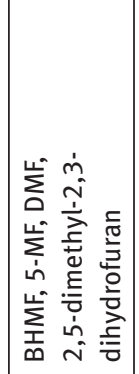 & 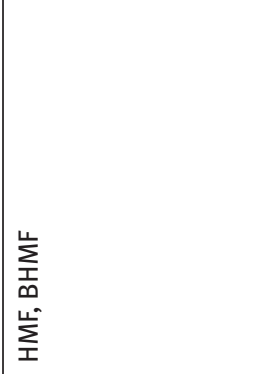 & 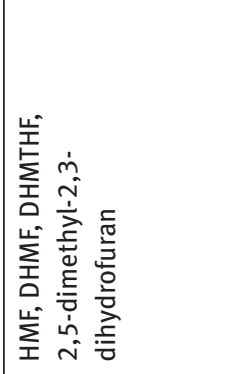 \\
\hline 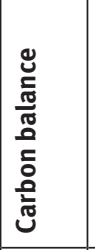 & 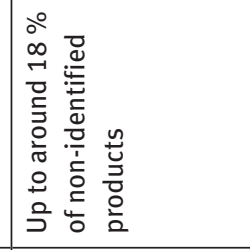 & 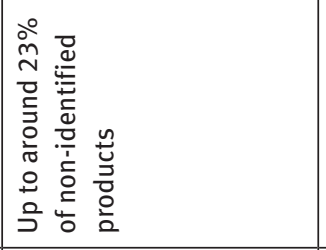 & 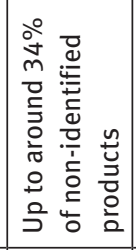 & 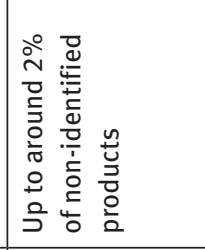 & 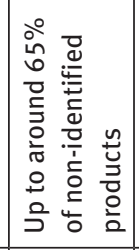 & 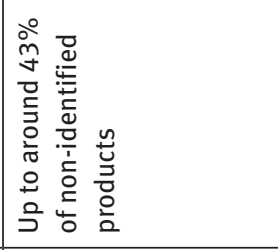 & . \\
\hline 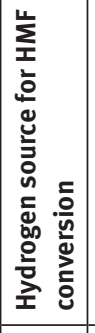 & . & 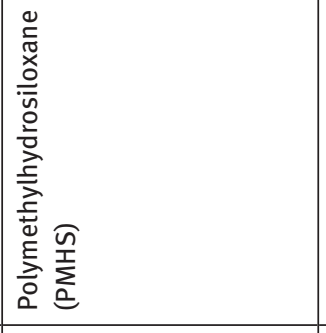 & 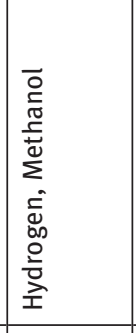 & 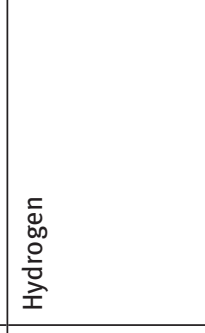 & 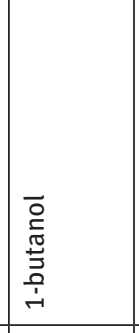 & 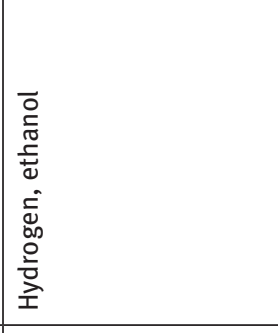 & 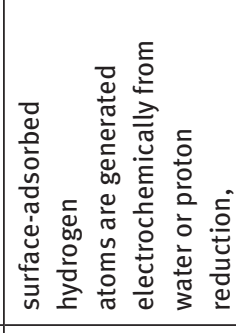 \\
\hline 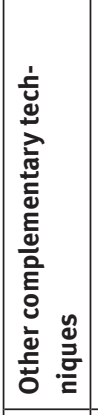 & . & 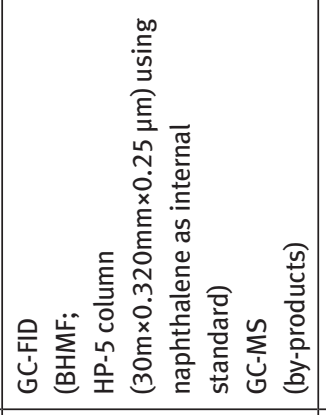 & & 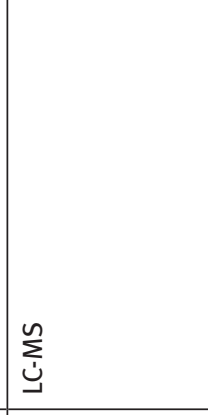 & 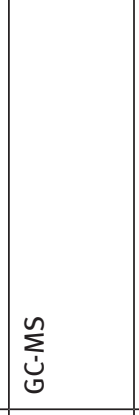 & 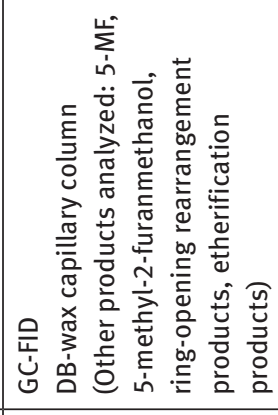 & 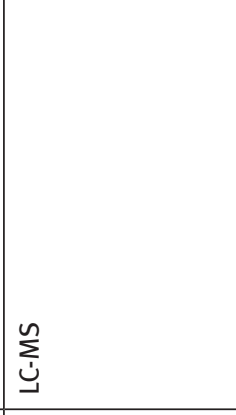 \\
\hline 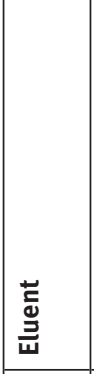 & 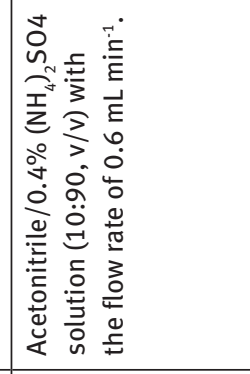 & & 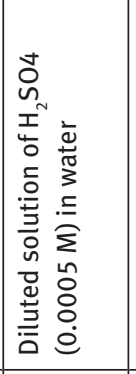 & 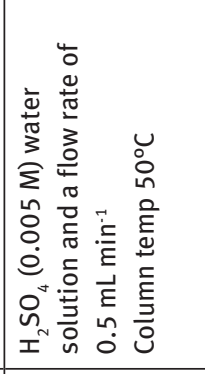 & 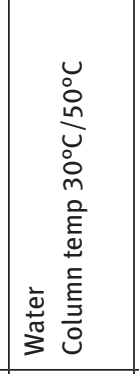 & & 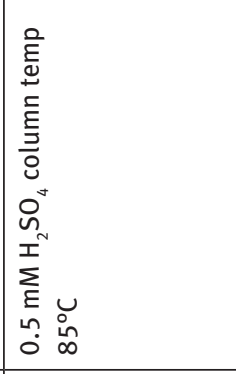 \\
\hline 㿤 & 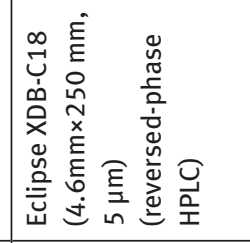 & 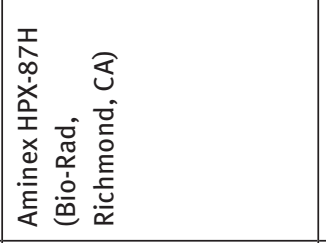 & 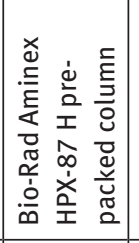 & 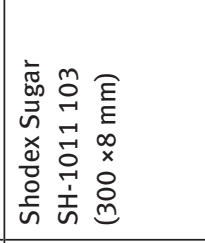 & 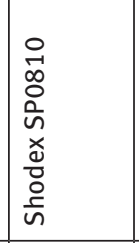 & 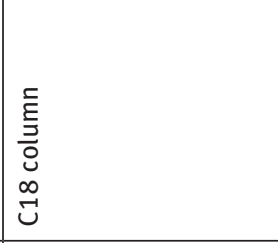 & 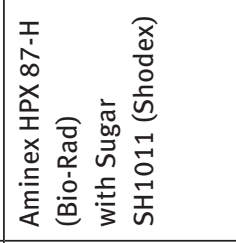 \\
\hline 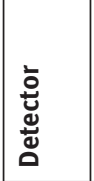 & 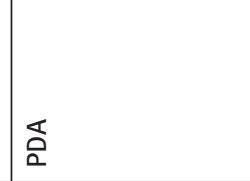 & 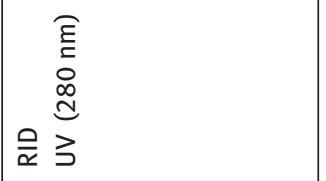 & 3 & $3 \frac{0}{\alpha}$ & 产 & 竞 & 只 \\
\hline
\end{tabular}




\begin{tabular}{|c|c|c|c|c|c|}
\hline$\ddot{\ddot{\varpi}}$ & $\underset{\infty}{\widetilde{\infty}}$ & $\vec{a}$ & 合 & $\stackrel{\square}{\circ}$ & $\widetilde{\sigma}$ \\
\hline 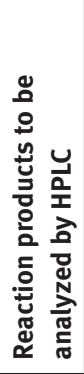 & 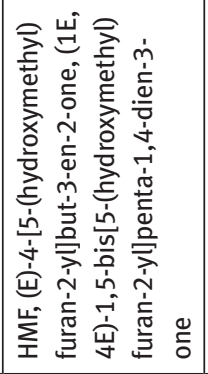 & 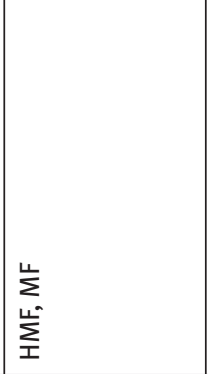 & 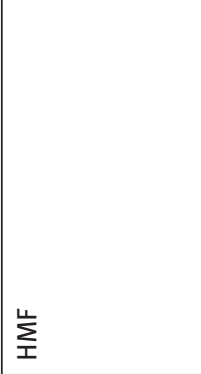 & $\sum_{I}^{L}$ & 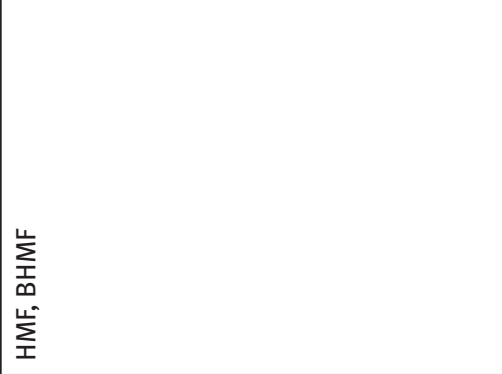 \\
\hline 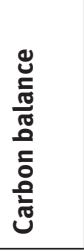 & 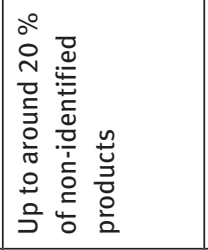 & & 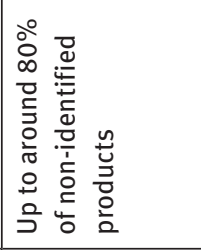 & 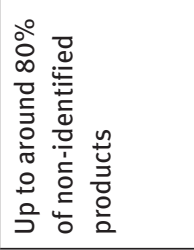 & . \\
\hline 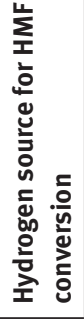 & 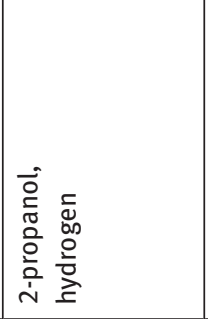 & 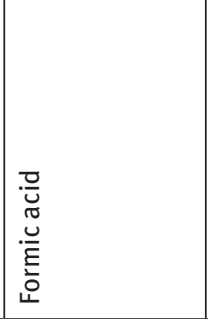 & 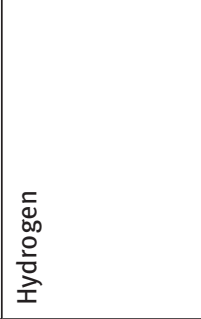 & 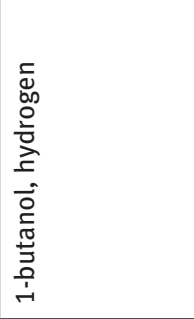 & 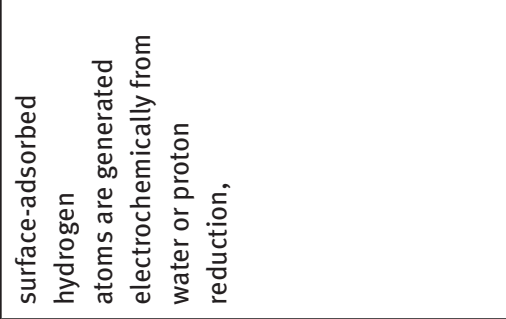 \\
\hline 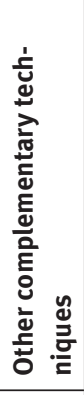 & 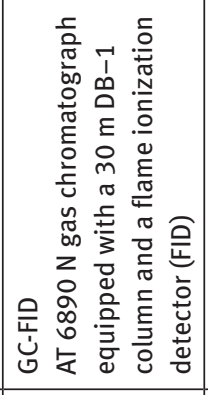 & 产 & 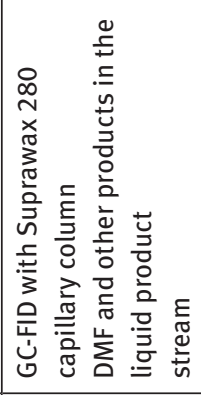 & 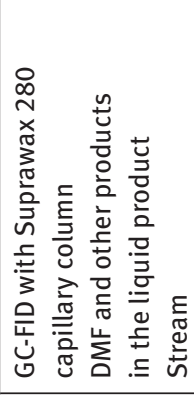 & 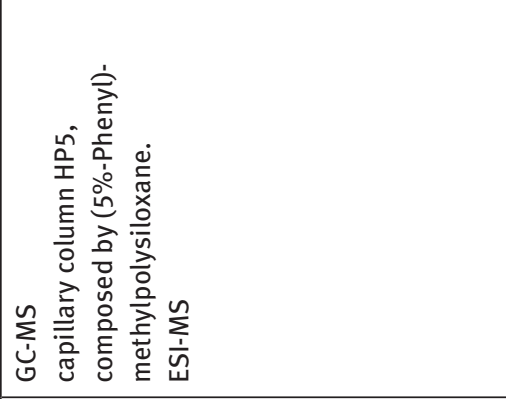 \\
\hline 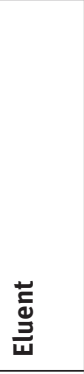 & 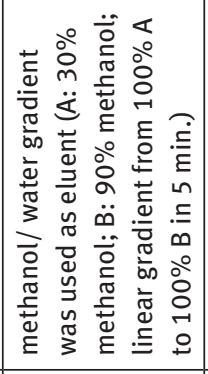 & 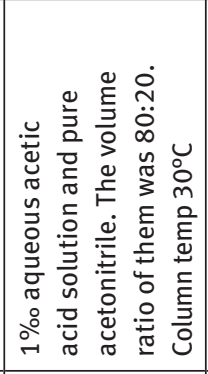 & & & 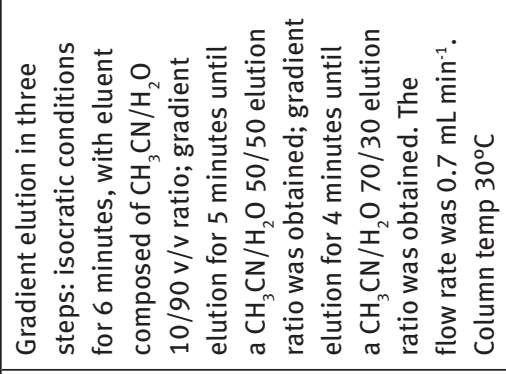 \\
\hline ह & 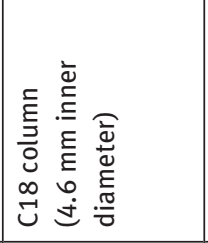 & 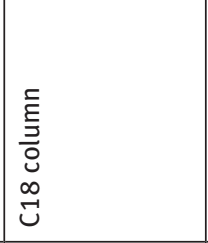 & \begin{tabular}{|l}
$\frac{T}{x}$ \\
$\frac{x}{0}$ \\
$\frac{1}{I}$ \\
\end{tabular} & 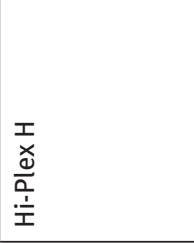 & 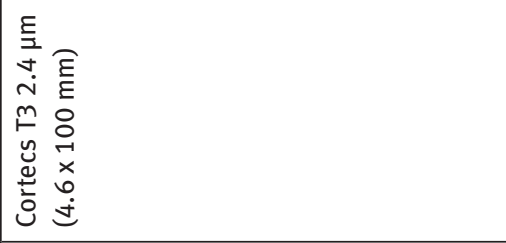 \\
\hline 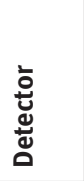 & 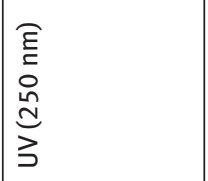 & 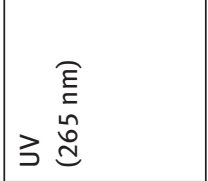 & $\cong$ & & 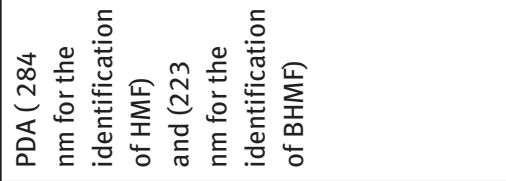 \\
\hline
\end{tabular}




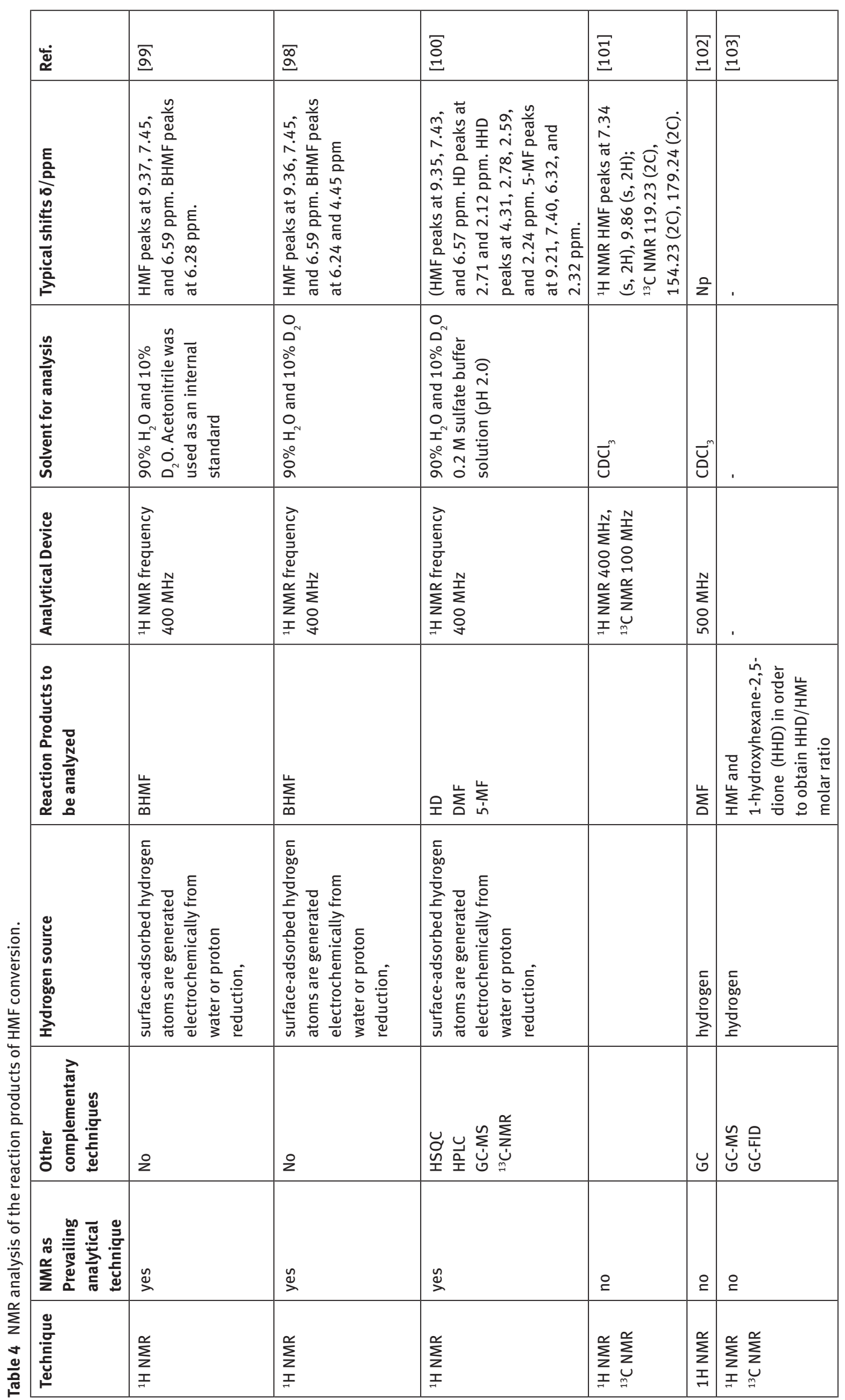


and $1600 \mathrm{~cm}^{-1}$ show $\mathrm{C}=\mathrm{C}$ stretching vibrations indicating the presence of aliphatic or aromatic structure. Finally, bands at 1600 and $1800 \mathrm{~cm}^{-1}$ are attributed to the presence of $\mathrm{C}=0$ groups, whereas bands between 1000 and $1100 \mathrm{~cm}^{-1}$ are assigned to $\mathrm{C}-\mathrm{O}$ stretching vibrations which can indicate the presence of e.g. ethers, alcohols or carboxylic acids.

In the HMF hydrodeoxygenation there are only very limited examples of the application of this method [96,97] and additionally, they are supported by other techniques like GC. HPLC with IR detector was used for HMF determination whereas all other products of hydrogenolysis of HMF were analyzed by GC (Table 4).

Carbon ${ }^{13} \mathrm{C}$ NMR and hydrogen ${ }^{1} \mathrm{H}$ NMR allow both qualitative and quantitative analysis of chemical structures. They are however used marginally, and their potential is mainly used for confirmation of the structure functionality and purity rather than the analysis of the reaction product range. The existing examples where this technique is used solely for following the reaction performance are limited to the analysis of one reaction product [98].

The concentration of HMF and BHMF, the product of its electrochemical or photoelectrochemical hydrogenation in water was estimated thanks to hydrogen NMR by the group of Roylance et al. [98] and Zhang et al. [99]. The measurements were performed using acetonitrile as an internal standard, and $90 \% \mathrm{H}_{2} \mathrm{O}$ and $10 \% \mathrm{D}_{2} \mathrm{O}$ were used as a solvent. ${ }^{1} \mathrm{H}$ signal originating from water was removed by the water suppression method. Then the respective ${ }^{1} \mathrm{H}$ NMR peaks allowed to determine the selectivity to the main reaction product and the HMF conversion. The identification of other possible reaction products was however omitted.

Another interesting example where the NMR technique was efficiently exploited for analysis was also used in the case of electrochemical reduction of HMF to HD, a hydrated derivative of DMF, which can be used for the production of terephthalic acid for polyethylene terephthalate (PET) [100]. Here the analysis of other main reaction products was also performed. In all those examples water was used as a reaction medium, often with the presence of inorganic salts working as a buffer, which could be potentially problematic for other chromatographic techniques.

\section{Conclusions and future outlook}

Conversion of HMF is a process of constantly growing interest. It is a difficult reaction from an analytical point of view due to the variety of formed products. Numerous analytical approaches have already been developed. Most of the studies however concentrate only on the most important reaction products, omitting the analysis of by-products. Information about the detailed product contributions therefore of high interest, as understanding all side reactions that can occur allows improving the whole process. The precise analysis includes a combined approach using several techniques. Gas chromatography coupled with various detectors (TCD, FID, MS) is the most frequently used method and allows both qualitative and quantitative understanding of most of the products. FTIR and NMR analyses additionally provide information on the functional groups and types of chemical bonds, which allows to complete the picture of reaction network and product distribution.

Besides the necessary complete analysis of gaseous or liquid products formed during the hydrodeoxygenation of HMF, we would like to emphasize that an extended analysis of the reaction products might also request to investigate on the deposition with time of solid or polymeric carbonaceous products at the catalyst surface, as well as to implement on-line product analysis. Indeed, while this might help in closing the carbon balance, this also influences the catalytic performance with potential impact on both conversion and selectivity patterns, as well as on stability and reusability issues. Whether academic or industrial investigations are concerned, it is worth keeping always in mind that the criteria for selecting the adequate analytical tool should include the analysis time. Indeed, due to the high number of products with close functions, the analysis might remain time-consuming when a good chromatographic product separation is desired. We believe that that information presented in this current review can also shed the light on the selection of adapted chromatographic techniques for other similar biomass-derived molecule hydrogenation processes.

Further, the continuous improvement of the analytical tools played a role - and is still expected to do so in the future - in the progress obtained in the last decades both from fundamental and applied points of view, notably by allowing faster and more sensitive detection of the large variety of the HMF hydrogenation side-products view.

\section{Acknowledgments}

The authors gratefully acknowledge that this work was financially supported by a grant SONATA BIS from the National Center of Science (NCN) in Krakow (Poland) (2016/22/E/ST4/00550). 


\section{References}

[1] Alonso DM, Wettstein SG, Dumesic J. Gamma-valerolactone, a sustainable platform molecule derived from lignocellulosic biomass. Green Chem. 2013;15:584-95.

[2] Li X, Xu R, Yang J, Nie S, Liu D, Liu Y, et al. Production of 5-hydroxymethylfurfural and levulinic acid from lignocellulosic biomass and catalytic upgradation. Ind Crops Prod. 2019;130:184-197.

[3] Ruppert AM, Weinberg K, Palkovits R. Hydrogenolysis Goes Bio: From Carbohydrates and Sugar Alcohols to Platform Chemicals. Angew Chem Int Ed. 2012;51:2564-601.

[4] Ruppert AM, Jędrzejczyk M, Potrzebowska N, Kaźmierczak K, Brzezińska M, Sneka-Płatek O, et al. Supported gold-nickel nano-alloy as a highly efficient catalyst in levulinic acid hydrogenation with formic acid as an internal hydrogen source. Catal Sci Technol. 2018;8:4318-31.

[5] Yan K, Yang Y, Chai J, Lu Y. Catalytic reactions of gammavalerolactone: A platform to fuels and value-added chemicals. Appl Catal B. 2015;179:292-304.

[6] Zhang B, Zhu Y, Ding G, Zheng H, Li Y. Selective conversion of furfuryl alcohol to 1,2-pentanediol over a Ru/MnOx catalyst in aqueous phase. Green Chem. 2012;14:3402-9.

[7] Wang H, Zhu C, Li D, Liu Q, Tan J, Wang C, et al. Recent advances in catalytic conversion of biomass to 5-hydroxymethylfurfural and 2, 5-dimethylfuran. Renew Sustain Energy Rev. 2019;103:227-47.

[8] Chen S, Wojcieszak R, Dumeignil F, Marceau E, Royer S. How Catalysts and Experimental Conditions Determine the Selective Hydroconversion of Furfural and 5-Hydroxymethylfurfural. Chem Rev. 2018;118(22):11023-117.

[9] Tong X, Ma Y, Li Y. Biomass into chemicals: conversion of sugars to furan derivatives by catalytic processes. Appl Catal A Gen. 2010;385:1-13.

[10] Alonso DM, Bond JQ, Dumesic JA. Catalytic conversion of biomass to biofuels. Green Chem. 2010;12:1493-513.

[11] Hu L, Lin L, Liu S. Chemoselective Hydrogenation of BiomassDerived 5-Hydroxymethylfurfural into the Liquid Biofuel 2,5-Dimethylfuran. Ind Eng Chem Res. 2014;53(24):9969-78.

[12] Lv G, Wang H, Yang Y, Li X, Deng T, Chen C, et al. Aerobic Selective Oxidation of 5-Hydroxymethyl-furfural over Nitrogen-doped Graphene Material with 2,2,6,6-Tetramethylpiperidin-oxyl as Cocatalyst. Catal Sci Technol. 2016;6:2377-2386.

[13] Mei N, Liu B, Zheng J, Lv K, Tang D, Zhang Z. A novel magnetic palladium catalyst for the mild aerobic oxidation of 5-hydroxymethylfurfural into 2,5-furandicarboxylic acid in water. Catal Sci Technol. 2015;5:3194-202.

[14] Jiang Y, Woortman AJ. A van Ekenstein G O R, Petrović D M, Loos K. Enzymatic Synthesis of Biobased Polyesters Using 2,5-Bis(hydroxymethyl)furan as the Building Block. Biomacromolecules. 2014;15(7):2482-93.
[15] Hu L, Xu J, Zhou S, He A, Tang X, Lin L, et al. Catalytic Advances in the Production and Application of Biomass-Derived 2,5-Dihydroxymethylfuran. ACS Catal. 2018;8(4):2959-80.

[16] Tian G, Daniel R, Li H, Xu H, Shuai S, Richards P. Laminar Burning Velocities of 2,5-Dimethylfuran Compared with Ethanol and Gasoline. Energy Fuels. 2010;24(7):3898-905.

[17] Kuster B F M. 5-Hydroxymethylfurfural (HMF). A Review Focusing on its Manufacture. Starch. 1990;42:314 -321

[18] Pedersen AT, Ringborg R, Grotkjaer T, Pedersen S, Woodley JM. Synthesis of 5-hydroxymethylfurfural (HMF) by acid catalyzed dehydration of glucose-fructose mixtures. Chem Eng J. 2015;273:455-64.

[19] Menegazzo F, Ghedini E, Signoretto M. 5-Hydroxymethylfurfural (HMF) Production from Real Biomasses. Molecules. 2018;23:2201.

[20] Rosatella AA, Simeonov SP, Frade R F M, Afonso C A M. 5-Hydroxymethylfurfural (HMF) as a building block platform: biological properties, synthesis and synthetic applications. Green Chem. 2011;13:754-93.

[21] de Souza RL, Yu H, Rataboul F, Essayem N. 5-Hydroxymethylfurfural (5-HMF) Production from Hexoses: Limits of Heterogeneous Catalysis in Hydrothermal Conditions and Potential of Concentrated Aqueous Organic Acids as Reactive Solvent System. Challenges. 2012;3:212-32.

[22] Yu IK, Tsang DC. Conversion of biomass to hydroxymethylfurfural: A review of catalytic systems and underlying mechanisms. Bioresour Technol. 2017;238:716-32.

[23] Pande A, Niphadkar P, Pandare K, Bokade V. Acid Modified H-USY Zeolite for Efficient Catalytic Transformation of Fructose to 5-Hydroxymethyl Furfural (Biofuel Precursor) in Methyl Isobutyl Ketone-Water Biphasic System. Energy Fuels. 2018;32:3783-91.

[24] Ordomsky VV, van der Schaaf J, Schouten JC, Nijhuis TA. Fructose Dehydration to 5-Hydroxymethylfurfural over Solid Acid Catalysts in a Biphasic System. ChemSusChem. 2012;5:1812-9.

[25] Xia H, Xu S, Yang L. Efficient conversion of wheat straw into furan compounds, bio-oils, and phosphate fertilizers by a combination of hydrolysis and catalytic pyrolysis. RSC Advances. 2017;7:1200-5.

[26] Chheda JN, Román-Leshkova Y, and Dumesic JA. Production of 5-hydroxymethylfurfural and furfural by dehydration of biomass-derived mono- and poly-saccharides. Green Chem., 2007;9:342-50

[27] Romo JE, Bollar NV, Zimmermann CJ, Wettstein SG. Conversion of Sugars and Biomass to Furans Using Heterogeneous Catalysts in Biphasic Solvent Systems. ChemCatChem. 2018;10:4805-16.

[28] Brzezińska M, Keller N, Ruppert AM. Self-tuned properties of CuZnO catalysts for hydroxymethylfurfural hydrodeoxygenation towards dimethylfuran production. Catal Sci Technol. 2020;10:658-70. 
[29] Ho TD, Zhang C, Hantao LW, Anderson JL. Ionic Liquids in Analytical Chemistry: Fundamentals, Advances, and Perspectives. Anal Chem. 2014;86:262-85.

[30] Lu Y, Li GS, Lu YC, Fan X, Wei XY. Analytical Strategies Involved in the Detailed Componential Characterization of Biooil Produced from Lignocellulosic Biomass. Int J Anal Chem. 2017;9298523.

[31] Mieure JP. Determining volatile organics in water. Environ Sci Technol. 1980;930-5.

[32] Lu Y, Wei XY, Liu FJ, Zong ZM, Rong LC, Zhao YP, et al. Evaluation of an Upgraded Bio-oil from the Pyrolysis of Rice Husk by Acidic Resin-catalyzed Esterification. Energy Sources A Recovery Util Environ Effects. 2014;36:575-81.

[33] Li X, Chanbasha B, Hian KL. Chemical reactions in liquid-phase microextraction. J Chromatogr A. 2009;1216:701-7.

[34] Cajka T, Showalter MR, Riddellova K, Fiehn O. Advances in Mass Spectrometry for Food Authenticity Testing, 2016, Woodhead Publishing Series in Food Science. Technology and Nutrition; 2016. pp. 171-200.

[35] Teixidó E, Santos FJ, Puignou L, Galceran MT. Analysis of 5-hydroxymethylfurfural in foods by gas chromatography-mass spectrometry. J Chromatogr A. 2016;1135:85-90.

[36] Wanner K, Höfner G. Mass Spectrometry in Medicinal Chemistry: Applications in Drug Discovery (Methods and Principles in Medicinal Chemistry). J Am Soc Mass Spectrom. 2008;19:R1-2.

[37] Agilent J\&W GC Column Selection Guide, Ref. 5990-9867, EN, Agilent Technologies Inc., USA, April 2012

[38] Gao Z, Fan G, Liu M, Yang L, Li F. Dandelion-like cobalt oxide microsphere-supported RuCo bimetallic catalyst for highly efficient hydrogenolysis of 5-hydroxymethylfurfural. Appl Catal B. 2018;237:649-59.

[39] Gao Z, Li C, Fan G, Yang L, Li F. Nitrogen-doped carbondecorated copper catalyst for highly efficient transfer hydrogenolysis of 5-hydroxymethylfurfural to convertibly produce 2,5-dimethylfuran or 2,5-dimethyltetrahydrofuran. Appl Catal B. 2018;226:523-33.

[40] Perret N, Grigoropoulos A, Zanella M, Manning TD, Claridge JB, Rosseinsky MJ. Catalytic Response and Stability of Nickel/ Alumina for the Hydrogenation of 5-Hydroxymethylfurfural in Water. ChemSusChem. 2016;9:521-31.

[41] Chimentão RJ, Oliva H, Belmar J, Morales K, Mäki-Arvela P, Wärna J, et al. Selective hydrodeoxygenation of biomass derived 5-hydroxymethylfurfural over silica supported iridium catalysts. Appl Catal B. 2019;241:270-83.

[42] Priecel P, Endot NA, Carà PD, Lopez-Sanchez JA. Fast Catalytic Hydrogenation of 2,5-Hydroxymethylfurfural to 2,5-Dimethylfuran with Ruthenium on Carbon Nanotubes. Ind Eng Chem Res. 2018;57:1991-2002.
[43] Zhu C, Liu Q, Li D, Wang H, Zhang C, Cui C, et al. Selective Hydrodeoxygenation of 5-Hydroxymethylfurfural to 2,5-Dimethylfuran over Ni Supported on Zirconium Phosphate Catalysts. ACS Omega. 2018;3:7407-17.

[44] Li D, Liu Q, Zhu C, Wang H, Cui C, Wang C, et al. Selective hydrogenolysis of 5-hydroxymethylfurfural to 2,5-dimethylfuran over $\mathrm{C} 0304$ catalyst by controlled reduction. J Chem. 2019;30:34-41.

[45] Yang Y, Liu Q, Li D, Tan J, Zhang Q, Wang C, et al. Selective hydrodeoxygenation of 5-hydroxymethylfurfural to 2,5-dimethylfuran on Ru-MoOx/C catalysts. RSC Advances. 2017;7:16311-8.

[46] Luo J, Monai M, Wang C, Lee JD, Duchoň T, Dvořák F, et al. Unraveling the surface state and composition of highly selective nanocrystalline $\mathrm{Ni}-\mathrm{Cu}$ alloy catalysts for hydrodeoxygenation of HMF. Catal Sci Technol. 2017;7:1735-43.

[47] Luo J, Arroyo-Ramírez L, Gorte RJ. Hydrodeoxygenation of HMF Over Pt/C in a Continuous Flow Reactor. AIChE. 2015;61:590-7.

[48] Luo J, Arroyo-Ramírez L, Wei J, Yun H, Murray CB, Gorte RJ. Comparison of HMF hydrodeoxygenation over different metal catalysts in a continuous flow reactor. Appl Catal A Gen. 2015;508:86-93.

[49] Luo J, Yun H, Mironenko AV, Goulas K, Lee JD, Monai M, et al. Mechanisms for High Selectivity in the Hydrodeoxygenation of 5-Hydroxymethylfurfural over PtCo Nanocrystals. ACS Catal. 2016;6:4095-104.

[50] Gyngazova MS, Negahdar L, Blumenthal LC, Palkovits $R$. Experimental and kinetic analysis of the liquid phase hydrodeoxygenation of 5-hydroxymethylfurfural to 2,5-dimethylfuran over carbon-supported nickel catalysts. Chem Eng Sci. 2017;173:455-64.

[51] Wiesfeld JJ, Kim M, Nakajima K, Hensen EJ. Selective hydrogenation of 5-hydroxymethylfurfural and its acetal with 1,3-propanediol to 2,5-bis(hydroxymethyl)furan using supported rhenium-promoted nickel catalysts in water. Green Chem. 2020;22:1229-38.

[52] Hu L, Li N, Dai X, Guo Y, Jiang Y, He A, et al. Highly efficient production of 2,5-dihydroxymethylfuran from biomass-derived 5-hydroxymethylfurfural over an amorphous and mesoporous zirconium phosphonate catalyst. J of Ener Chem. 2019;37:82-92.

[53] Hu L, Dai X, Li N, Tang X, Jiang Y. Highly selective hydrogenation of biomass-derived 5-hydroxymethylfurfural into 2,5-bis(hydroxymethyl)furan over an acid-base bifunctional hafnium-based coordination polymer catalyst. Sustain Energy Fuels. 2019;3:1033-41.

[54] Hu L, Li T, Xu J, He A, Tang X, Chu X, et al. Catalytic transfer hydrogenation of biomass-derived 5-hydroxymethylfurfural into 2,5-dihydroxymethylfuran over magnetic zirconium-based coordination polymer. Chem Eng J. 2018;352:110-9. 
[55] Shi J, Wang Y, Yu X, Du W, Hou Z. Production of 2,5-dimethylfuran from 5-hydroxymethylfurfural over reduced graphene oxides supported Pt catalyst under mild conditions. Fuel. 2016;163:74-9.

[56] Kong X, Zhu Y, Zheng H, Zhu Y, Fang Z. Inclusion of Zn into Metallic Ni Enables Selective and Effective Synthesis of 2,5-Dimethylfuran from Bioderived 5-Hydroxymethylfurfural. ACS Sustain Chem \& Eng. 2017;5:11280-9.

[57] Li J, Liu J, Liu H, Xu G, Zhang J, Liu J, et al. Selective Hydrodeoxygenation of 5-Hydroxymethylfurfural to 2,5-Dimethylfuran over Heterogeneous Iron Catalysts. ChemSusChem. 2017;10:1436-47.

[58] Hu L, Yang M, Xu N, Xu J, Zhou S, Chu X, et al. Selective transformation of biomass-derived 5-hydroxymethylfurfural into 2,5-dihydroxymethylfuran via catalytic transfer hydrogenation over magnetic zirconium hydroxides. Korean J Chem Eng. 2018;35(1):99-109.

[59] Wei J, Cao X, Wang T, Liu H, Tang X, Zeng X, et al. Catalytic transfer hydrogenation of biomass derived 5-hydroxymethylfurfural into 2,5-bis(hydroxymethyl)furan over tunable Zr-based bimetallic catalysts. Catal Sci Technol. 2018;8:4474-84.

[60] Wang T, Wei J, Liu H, Feng Y, Tang X, Zeng X, et al. Synthesis of renewable monomer 2, 5-bishydroxymethylfuran from highly concentrated 5-hydroxymethylfurfural in deep eutectic solvents. J Ind Eng Chem. 2020;81:93-8.

[61] Luo J, Lee JD, Yun H, Wang C, Monai M, Murray CB, et al. Base metal-Pt alloys: A general route to high selectivity and stability in the production of biofuels from HMF. Appl Catal B. 2016;199:439-46.

[62] Nakagawa Y, Takada K, Tamura M, Tomishige K. Total Hydrogenation of Furfural and 5-Hydroxymethylfurfural over Supported Pd-Ir Alloy Catalyst. ACS Catal. 2014;4:2718-26.

[63] Li G, Sun Z, Yan Y, Zhang Y, Tang Y. Direct Transformation of HMF into 2,5-Diformylfuran and 2,5-Dihydroxymethylfuran without an External Oxidant or Reductant. ChemSusChem. 2017;10:494-8.

[64] Bottari G, Kumalaputri AJ, Krawczyk KK, Feringa BL, Heeres HJ, Barta K. Copper-Zinc Alloy Nanopowder: A Robust Precious-Metal-Free Catalyst for the Conversion of 5-Hydroxymethylfurfural. ChemSusChem. 2015;8:1323-7.

[65] Sun K, Shao Y, Li Q, Liu Q, Wu W, Wang Y, et al. Cu-based catalysts for hydrogenation of 5-hydroxymethylfurfural: understanding of the coordination between copper and alkali/alkaline earth additives. Molec Catal. 2019;474:110407.

[66] Yang Y, Liu H, Li S, Chen C, Wu T, Mei Q, et al. Hydrogenolysis of 5-Hydroxymethylfurfural to 2,5-Dimethylfuran under Mild Conditions without Any Additive. ACS Sustain Chem\& Eng. 2019;7(6):5711-6.
[67] Zhang J, Chen J. Selective transfer hydrogenation of biomass-based furfural and 5-hydroxymethylfurfural over hydrotalcite-derived copper catalysts using methanol as hydrogen donor. ACS Sustain Chem\& Eng. 2017;5(7):5982-93.

[68] Yu L, He L, Chen J, Zheng J, Ye L, Lin H, et al. Robust and Recyclable Nonprecious Bimetallic Nanoparticles on Carbon Nanotubes for the Hydrogenation and Hydrogenolysis of 5-Hydroxymethylfurfural. ChemCatChem. 2015;7:1701-7.

[69] Hu L, Tang X, Xu J, Wu Z, Lin L, Liu S. Selective Transformation of 5 -Hydroxymethylfurfural into the Liquid Fuel 2,5-Dimethylfuran over Carbon-Supported Ruthenium. Ind Eng Chem Res. 2014;53(8):3056-64.

[70] Chen N, Zhu Z, Su T, Liao W, Deng C, Ren W, et al. Catalytic hydrogenolysis of hydroxymethylfurfural to highly selective 2,5-dimethylfuran over FeCoNi/h-BN catalyst. Chem Eng J. 2020;381:122755.

[71] Sun Y, Xiong C, Liu Q, Zhang J, Tang X, Zeng X, et al. Catalytic Transfer Hydrogenolysis/Hydrogenation of Biomass-Derived 5-Formyloxymethylfurfural to 2, 5-Dimethylfuran Over $\mathrm{Ni}$-Cu Bimetallic Catalyst with Formic Acid As a Hydrogen Donor. Ind Eng Chem Res. 2019;58:5414-22.

[72] Liao W, Zhu Z, Chen N, Su T, Deng C, Zhao Y, et al. Highly active bifunctional Pd-Co9S8/S-CNT catalysts for selective hydrogenolysis of 5-hydroxymethylfurfural to 2,5-dimethylfuran.

Molec Catal. 2020;482:110756.

[73] Zhang F, Liu Y, Yuan F, Niu X, Zhu Y. Efficient Production of the Liquid Fuel 2,5-Dimethylfuran from 5-Hydroxymethylfurfural in the Absence of Acid Additive over Bimetallic PdAu Supported on Graphitized Carbon. Energy Fuels. 2017;31:6364-73.

[74] Long J, Zhao W, Xu Y, Li H, Yang S. Carbonate-Catalyzed Room-Temperature Selective Reduction of Biomass-Derived 5-Hydroxymethylfurfural into 2,5-Bis(hydroxymethyl)furan. Catalysts. 2018;8:633.

[75] Yang P, Xia Q, Liu X, Wang Y. Catalytic transfer hydrogenation/hydrogenolysis of 5-hydroxymethylfurfural to 2,5-dimethylfuran over $\mathrm{Ni}-\mathrm{Co} / \mathrm{C}$ catalyst. Fuel. 2017;187:159-66.

[76] Yang P, Xia Q, Liu X, Wang Y. High-yield production of 2,5-dimethylfuran from 5-hydroxymethylfurfural over carbon supported Ni-Co bimetallic catalyst. J Chem. 2016;206.

[77] Akmaz S, Esen M, Sezgin E, Koc SN. Efficient manganese decorated cobalt based catalysts for hydrogenation of 5-hydroxymethylfurfural (HMF) to 2,5-dimethylfuran (DMF) biofuel. Can J Chem Eng. 2019;1-9.

[78] Mhadmhan S, Franco A, Pineda A, Reubroycharoen P, Luque R. Continuous Flow Selective Hydrogenation of 5-Hydroxymethylfurfural to 2,5-Dimethylfuran Using Highly Active and Stable $\mathrm{Cu}-\mathrm{Pd} /$ Reduced Graphene Oxide. ACS Sustain Chem \& Eng. 2019;7:14210-6. 
[79] Srivastava S, Jadeja GC, Parikh J. Synergism studies on alumina-supported copper-nickel catalysts towards furfural and 5-hydroxymethylfurfural hydrogenation. J Mol Catal Chem. 2017;426:244-56.

[80] Srivastava S, Jadeja GC, Parikh J. Influence of supports for selective production of 2,5-dimethylfuran via bimetallic copper-cobalt catalyzed 5-hydroxymethylfurfural hydrogenolysis. Chin J Catal. 2017;38:699-709.

[81] Ly N, Al-Shamery K, Chan-Thaw CE, Prati L, Carniti P, Gervasini A. Impact of Support Oxide Acidity in Pt-Catalyzed HMF Hydrogenation in Alcoholic Medium. Catal Lett. 2017;147:345-59.

[82] Nagpure AS, Lucas N, Chilukuri SV. Efficient Preparation of Liquid Fuel 2,5-Dimethylfuran from Biomass-Derived 5 -Hydroxymethylfurfural over Ru-NaY Catalyst. ACS Sustain Chem\& Eng. 2015;3:2909-16.

[83] Saha B, Bohn CM, Abu-Omar MM. Zinc-Assisted Hydrodeoxygenation of Biomass-Derived 5-Hydroxymethylfurfural to 2,5-Dimethylfuran. ChemSusChem. 2014;7:3095-101.

[84] Zhu C, Wang H, Li H, Cai B, Lv W, Cai C, et al. Selective Hydrodeoxygenation of 5-Hydroxymethylfurfural to 2,5-Dimethylfuran over Alloyed Cu-Ni Encapsulated in Biochar Catalysts. ACS Sustain Chem\& Eng. 2019;7:19556-69.

[85] Egeblad K, Rass-Hansen J, Marsden CC, Taarning E, Christensen $\mathrm{CH}$. Heterogeneous catalysis for productionof value-added chemicals from biomass. Catalysis. 2009;21:13-5.

[86] Xu Z, Cheng A, Xing X, Zong M, Bai Y, Li N. Improved synthesis of 2,5-bis(hydroxymethyl)furan from 5-hydroxymethylfurfural using acclimatized whole cells entrapped in calcium alginate. Bioresour Technol. 2018;262:177-83.

[87] Pupovac K, Palkovits R. Cu/MgAl2O4 as Bifunctional Catalyst for Aldol Condensation of 5-Hydroxymethylfurfural and Selective Transfer Hydrogenation. ChemSusChem. 2013;6:2103-10.

[88] Mishra DK, Lee HJ, Truong CC, Kim J, Suh Y, Baek J, et al. $\mathrm{Ru} / \mathrm{MnC} 02 \mathrm{O} 4$ as a catalyst for tunable synthesis of 2,5-bis(hydroxymethyl) furan or 2,5-bis(hydroxymethyl) tetrahydrofuran from hydrogenation of 5-hydroxymethylfurfural. Molec Catal. 2020;484:110722.

[89] Hu D, Hu H, Zhou H, Li G, Chen C, Zhang J, et al. The effect of potassium on $\mathrm{Cu} / \mathrm{Al} 2 \mathrm{O} 3$ catalysts for the hydrogenation of 5-hydroxymethylfurfural to 2,5-bislJhydroxymethyl)furan in a fixed-bed reactor. Catal Sci Technol. 2018;8:6091-9.

[90] Kwon Y, Birdja YY, Raoufmoghaddam S, Koper MT. Electrocatalytic Hydrogenation of 5-Hydroxymethylfurfural in Acidic Solution. ChemSusChem. 2015;8:1745-51.

[91] Sun G, An J, Hu H, Li C, Zuo S, Xia H. Green catalytic synthesis of 5-methylfurfural by selective hydrogenolysis of 5-hydroxymethylfurfural over size-controlled Pd nanoparticle catalysts. Catal Sci Technol. 2019;9:1238-44.
[92] De Luna GS, Ho PH, Lolli A, Ospitali F, Albonetti S, Fornasari $\mathrm{G}$, et al. Ag electrodeposited on $\mathrm{Cu}$ open-cell foams for the selective electroreduction of 5-hydroxymethylfurfural. ChemElectroChem. 2020;7:1238-47.

[93] Chen J, Ge Y, Guo Y, Chen J. Selective hydrogenation of biomass-derived 5-hydroxymethylfurfural using palladium catalyst supported on mesoporous graphitic carbon nitride. J Energ Chem. 2018;27:283-9.

[94] Zhao W, Wu W, Li H, Fang C, Yang T, Wang Z, et al. Quantitative synthesis of 2,5-bis(hydroxymethyl)furan from biomassderived 5-hydroxymethylfurfural and sugars over reusable solid catalysts at low temperatures. Fuel. 2018;217:365-9.

[95] Alamillo R, Tucker M, Chia M, Pagán-Torres Y, Dumesic J. The selective hydrogenation of biomass-derived 5-hydroxymethylfurfural using heterogeneous catalysts. Green Chem. 2012;14:1413-9.

[96] Iriondo A, Mendiguren A, Güemez MB, Requies J, Cambra JF. 2,5-DMF production through hydrogenation of real and synthetic5-HMF over transition metal catalysts supported on carriers with different nature. Catal Today. 2017;279:286-95.

[97] Requies JM, Frias M, Cuezva M, Iriondo A, Agirre I, Viar N. Hydrogenolysis of 5-Hydroxymethylfurfural To Produce 2,5-Dimethylfuran over ZrO2 Supported $\mathrm{Cu}$ and RuCu Catalysts. Ind Eng Chem Res. 2018;57:11535-46.

[98] Roylance JJ, Kim TW, Choi K. Efficient and Selective Electrochemical and Photoelectrochemical Reduction of 5-Hydroxymethylfurfural to 2,5-Bis(hydroxymethyl)furan using Water as the Hydrogen Source. ACS Catal. 2016;6:1840-7.

[99] Zhang L, Zhang F, Michel FC, Co AC. Efficient Electrochemical Hydrogenation of 5-Hydroxymethylfurfural to 2,5-Bis(hydroxymethyl)furan on Ag-Displaced Nanotextured Cu Catalysts. ChemElectroChem. 2019;6:4739-49.

[100] Roylance JJ, Choi K. Electrochemical Reductive Biomass Conversion: direct Conversion of 5-hydroxymethylfurfural (HMF) to 2,5-hexanedione (HD) via Reductive Ring-opening. Green Chem. 2016;18:2956-60.

[101] Lv G, Wang H, Yang Y, Deng T, Chen C, Zhu Y, et al. Graphene Oxide A Convenient Metal-Free Carbocatalyst for Facilitating Aerobic Oxidation of 5-Hydroxymethylfurfural into 2, 5-Diformylfuran. ACS Catal. 2015;5(9):5636-46.

[102] Tzeng T, Lin C, Pao C, Chen J, Nuguid RJ, Chung P. Understanding catalytic hydrogenolysis of 5-hydroxymethylfurfural (HMF) to 2,5-dimethylfuran (DMF) using carbon supported Ru catalysts. Fuel Process Technol. 2020;199:106225.

[103] Ramos R, Grigoropoulos A, Griffiths BL, Katsoulidis AP, Zanella M, Manning TD, et al. Selective conversion of 5-hydroxymethylfurfural to diketone derivatives over Beta zeolite-supported Pd catalysts in water. J Catal. 2019;375:224-33. 